\title{
Microwave Irradiation Induces Oxygen Vacancy in Metal Oxides based Materials and Devices: A Review
}

\author{
Kabongo $\mathrm{GL}^{1,2^{*}}$, Khawula TNY ${ }^{1}$, Thokozani $\mathrm{T}^{1}$, Nyongombe $\mathrm{EG}^{3}$, Ozoemena $\mathrm{K}^{1}$ and Dhlamini $\mathbf{S}^{3}$ \\ ${ }^{1}$ Molecular Sciences Institute, School of Chemistry, University of the Witwatersrand, Johannesburg 2050, South Africa \\ ${ }^{2}$ Department de Physique, Universite Pedagogique Nationale, Republique Democratique du Congo \\ ${ }^{3}$ Department of Physics, University of South Africa, South Africa
}

*Corresponding author: Guy Kabongo, Molecular Sciences Institute, School of Chemistry, University of the Witwatersrand, Johannesburg, South Africa, Tel: +27713392577; E-mail: Guy.Kabongo@wits.ac.za, geekale@gmail.com

Received date: July 5, 2018; Accepted date: August 9, 2018; Published date: August 17, 2018

Copyright: (c) 2018 Kabongo GL, et al. This is an open-access article distributed under the terms of the Creative Commons Attribution License, which permits unrestricted use, distribution, and reproduction in any medium, provided the original author and source are credited.

\begin{abstract}
A mini-review of defects formation and engineering in energy and sensor materials through intentional doping and microwave irradiation is presented. Intensive research interest has been observed in the development of Transition Metal Oxides (TMOs) energy and sensor materials for industrial applications such as energy generation, energy storage and sensor devices. A variety of selected notable reports are organized into sections depicting structural, microstructural, luminescent and electronic properties of TMO materials and devices, regardless of their deep synthetic chemistry. There are three types of Oxygen Vacancies (VO) related to TMO materials among which neutrally ionized $\mathrm{V} 0$, singly ionized $\mathrm{Vo}^{1+}$, and doubly ionized $\mathrm{Vo}^{2+}$. Oxygen vacancies $(\mathrm{V})$ have been characterized using several experimental techniques such as X-ray diffraction, Thermo-Gravimetric Analysis (TGA), Ultra-Violet Visible Spectroscopy (UV-Vis), Photoluminescence (PL) spectroscopy, Raman spectroscopy, Electron Spin Resonance (ESR), Electron Energy Loss Spectroscopy (EELS) and X-ray Photoelectron spectroscopy (XPS). High resolution XPS O 1s core levels analysis is one of the most accurate analytical techniques to characterize VO in conjunction with other techniques. The deconvolution of $\mathrm{O} 1 \mathrm{~s}$ core levels using a Gaussian function into three peaks Lattice oxygen $(\mathrm{OL})$, surface hydroxyl oxygen $(\mathrm{O}-\mathrm{OH})$ and adsorbed oxygen $(\mathrm{OS})$ has been widely used to correlate XPS to XRD, UV-Vis, PL and Raman data. This review summarizes the representative reports of VO formation via intentional doping or microwave irradiation in TMOs.
\end{abstract}

Keywords: Oxygen vacancies; TMOs; Doping; Microwave; Energy materials; Sensors

\section{Introduction}

Over the past two decades, oxygen vacancies (VO) have been widely reported to dramatically alter structural, luminescent, catalytic and electronic properties of materials applied in a variety of applications such as energy, sensors and display technologies [1-9]. These defects classified as point defects are till now the subject of a hot controversy on their natural origin among the scientific community worldwide due to the inherent challenges related to materials synthesis and characterization management in the vast majority of experimental fields. Oxygen vacancies exist in three states, namely neutrally ionized $\mathrm{V}_{0}$, singly ionized $\mathrm{V}^{1+}$ and doubly ionized $\mathrm{V}^{2+}$, the first and the former are stable $(10,11)$ (Figure 1). Hitherto, fundamental studies have been devoted to elucidate the factors characterizing point defects, most of them have been investigated by first principle calculations $[11,12]$. The main factors are the formation energy and defect concentration, the former is well described in thermodynamic equilibrium by a Boltzmann distribution while at the same time it is closely related to the formation energy, defects with high formation energy are formed in low concentration [11]. The formation energy of point defects should not be considered as a constant due to its dependence to growth conditions. Previous studies have revealed that the formation energy of an oxygen vacancy depends on the abundance of the parent atoms found in the material and becomes more complex when the oxygen vacancy is charged because of the non-negligible effect of the electron chemical potential [11].

The major role of oxygen vacancy on the modification of electronic properties of materials has been discussed in a considerable volume of reports from fundamental studies to experimental investigations. The key fields of interest are primarily energy, secondly sensors and luminescent materials. In all these fields, TMOs have demonstrated exceptional performances, among them $\mathrm{ZnO}, \mathrm{TiO}_{2}, \mathrm{NiO}, \mathrm{MnO}, \mathrm{CdO}$, $\mathrm{Fe}_{2} \mathrm{O}_{4}, \mathrm{SnO}_{2}, \mathrm{Co}_{3} \mathrm{O}_{4}$ [13-53] are gaining momentum. However, fewer have successfully achieved intentional doping using foreign atoms to control intrinsic materials properties [49-51,54].

More importantly, innovative bi- and tri-metallic multifunctional nanostructure and heterostructure materials have been designed and constructed to achieve extraordinary device performances in selected topics such as reticular chemistry, electrochemical double-layer capacitors (EDLC), pseudo-capacitors, electrochemical sensors, white light emitting devices, solar cells, lithium-ion batteries, lithium-sulfur batteries, photoelectrochemical cells and gas sensors [55-66].

The growing interest in device's performance engineering stems among others from the possibility to intentionally tailor and control their oxygen vacancy content. To achieve such goal there is a critical need to judiciously undertake synthesis and characterization of materials to be investigated in clean environment and also deeply understand the effects of sample treatment on its lattice structure properties. To date several factors have been identified to remarkably alter the lattice structure properties of TMOs, among the major are the 
pressure, temperature and gas treatment environment. Moreover, the exposure time to electromagnetic radiations sources such as Deep UV lamps, induction sources, and microwave reactors have been found to also contribute to the alteration of materials primitive lattice structure. It should be noted that these lattice structure alterations may have non- negligible direct contribution to the variation of oxygen vacancy content as it can be achieved elsewhere from simple conventional doping processes. Owing to the close correlation between materials lattice structure and electronic band-structure properties, one should have a precise understanding of the material band-structure in order to constructively and optimally describe research observations and findings.

Through structural doping the formation of oxygen defective sites has been successfully achieved, while the resulting tensile strain was revealed by the expansion of material lattice structure [67]. In fact, Xray diffraction analysis of the lattice structure quality and crystallographic fingerprint may lead to the detection of possible alteration of the lattice structure resulting from foreign atoms insertion [68]. In their report, Kaur et al [68] demonstrated that doping a transition metal oxide host material with foreign atoms resulted in a tensile strain observed from XRD peak shift toward lower angles which leads to better materials properties later on. Moreover, the slight alteration observed in the lattice structure may have dramatic impact in the materials performance enhancement or degradation, depending of the targeted application.

Interestingly, Kumar et al. [69], have recently achieved lattice structure expansion via microwave irradiation, this process leads to the realization of high performing electrochemical spinel cathode materials for energy storage applications. Likewise, Mesfin et al. [70] and Jafta et al. [71] reported the same phenomenon and achieved exceptional electrochemical properties. Several factors have been identified by these authors to be responsible for these unique observations but oxygen vacancy increase should be seriously considered as the most plausible cause from a fundamental understanding [71].

Hence, the selection of a particular material synthetic method is of particular importance to the formation and careful control of oxygen vacancy. To date synthesis assisted with microwave treatment has proven to be one of the most effective approaches to meet such performance [70,71]. Microwave irradiation has demonstrated numerous advantages over other conventional materials processing such as fast and effective heating during chemical reactions, high product yield and environmental benign [72-74]. During microwave irradiation, a direct diffusion of electromagnetic wave energy to the material occurs via molecular interaction with the electric and magnetic field vectors of microwaves generated by a magnetron which produces waves in the frequency range of $300 \mathrm{MHz}-300 \mathrm{GHz}(\lambda: 1 \mathrm{~m}$ $1 \mathrm{~mm}$ ) (Figure 2). It is plausible that during the interaction of microwaves with the material nonequilibrium processes occur, the formation of oxygen deficient sites are then promoted in the material lattice structure consecutively to entropy-driven desorption of lattice oxygen in the lattice structure $[75,76]$ (Figure 3). Seminal studies have established that TMOs are among the best microwave absorbers and that their electrical resistance decreases with temperature increase and that microwave energy heats TMOs better than metals due to their low electric field penetration [77].

This review covers recent studies that focus on spectroscopic investigation of the versatile effects of oxygen vacancy on intrinsic properties of TMO materials for energy conversion, energy storage, sensors and solid state lighting. Special attention was devoted to XPS O 1 s core level analysis of oxygen vacancy using GAUSSIAN function deconvolution.

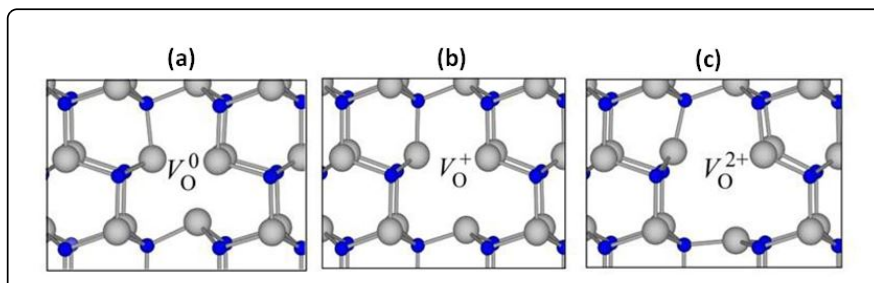

Figure 1: Local Atomic relaxations domain of oxygen vacancy in the (a) neutrally, (b) singly and (c) doubly ionized states. Reproduced with permission from ref. [78]. Copyright 2009 IOP publishing ltd.

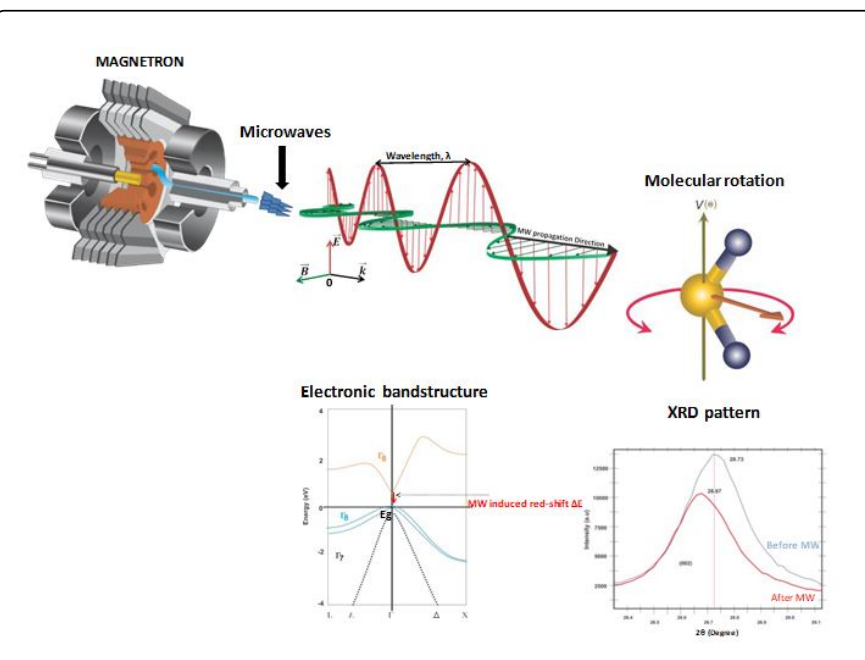

Figure 2: Proposed schematic diagram describing the mechanism of oxygen vacancy formation via microwave irradiation and its effect on lattice structure and electronic band- structure. Eg and $\Delta \mathrm{E}$ represent the energy gap and the quantified red-shift resulting from microwave irradiation which is shown by the red arrow.

\section{Formation of Oxygen Vacancy}

\section{Structural doping}

In a recent study, it has been demonstrated that using dopants one can tune oxygen vacancy in TMO base devices, precisely studies revealed that p-type dopants introduced holes into the system to lower significantly the formation energy of oxygen vacancy [85]. Several other methods have been successfully used to dope transition metal oxide based materials and devices and hence generate oxygen vacancies, such as combustion synthesis, solution- combustion, solid state reaction, sol-gel [86-88], co-precipitation, hydrothermal [89], sonochemical, chemical vapor deposition, plasma enhanced chemical deposition, RF magnetron sputtering, evaporation, electrochemical synthesis, spin coating, spray pyrolysis, and spray coating, etc. Park et al. [90] have successfully doped $\mathrm{ZnO}$ with $\mathrm{Co}^{2+}$ ions and remarkably analyzed the variation of $\mathrm{VO}$ in the undoped and Co-doped $\mathrm{ZnO}$ samples via Maximum entropy method (MEM) using electron density distribution derived from Rietveld refinement. The authors found that 
the $\mathrm{ZnO}$ unit cell volume was increased with $\mathrm{Co}^{2+}$ doping concentration and that consecutively the amount of $\mathrm{VO}$ increased up to a certain limit before dropping for higher doping concentration. The author faced a challenge to completely assigned the abrupt increase observed in the lowest $\mathrm{Co}^{2+}$ doping concentration and stated that further analysis were needed. It is plausible that $\mathrm{Co}^{2+}$ ions may have reached its saturation limit in the $\mathrm{ZnO}$ crystal lattice below $5 \mathrm{~mol} \%$ and above $1 \mathrm{~mol} \%$ and this could not lead to a continuous increase in VO content probably due to the segregation of $\mathrm{Co}^{2+}$ ions which are very likely to have formed islands of dopants in the crystal lattice instead of bonding.

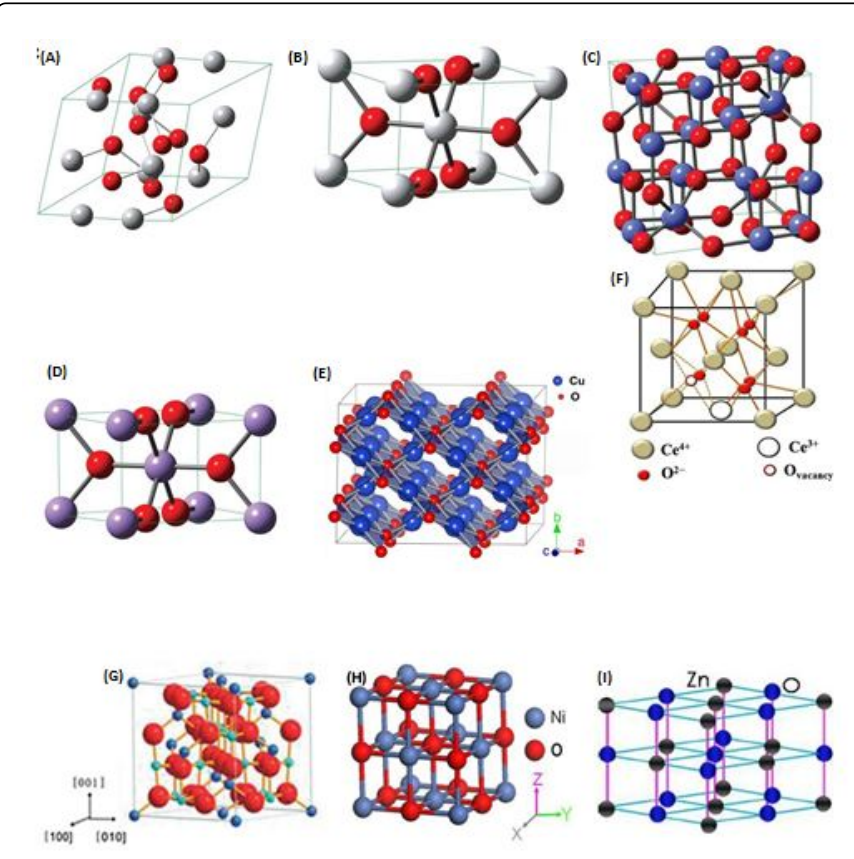

Figure 3: The crystal structures of (A) $\mathrm{TiO}_{2}$, (B) $\mathrm{Cr}_{2} \mathrm{O}_{3}$, (C) $\mathrm{V}_{2} \mathrm{O}_{3}$, (D) $\mathrm{MnO}_{2}$. Reproduced with permission from ref. [79]. Copyright 2015 The Royal Society of Chemistry. (E) Refined Crystal structure of the $\mathrm{CuO}$ unit cell. Reproduced with permission from ref. [80]. Copyright 2014 Springer Nature Publishing Group. (F) Schematic model of the $\mathrm{CeO}_{2}$ structure showing $\mathrm{Ce}^{3+}$-ions and oxygen vacancy. The whitish color ball is $\mathrm{Ce}^{4+}$; the red color ball is $\mathrm{O}^{2-}$ on the lattice site; the red color circled ball is oxygen vacancy; the unfilled white ball represents $\mathrm{Ce}^{3+}$ on the lattice site formed after removing oxygen either from surface or from the interior of $\mathrm{CeO}_{2}$. Reproduced with permission from ref. [81]. Copyright 2017 Springer Nature Publishing Group. (G) Atomic configurations for the unit cell of spinel $\mathrm{Co}_{3} \mathrm{O}_{4}$. Reproduced with permission from ref. [82]. Copyright 2014 The Royal Society of Chemistry. (H) The cubic $\mathrm{NiO}$ crystal structure. Reproduced with permission from ref. [83]. Copyright 2015 Elsevier Ltd (I) A schematic representation of wurtzite $\mathrm{ZnO}$ crystal structure. The $\mathrm{Zn}$ and $\mathrm{O}$ atoms are marked as well in the schematic with ash and blue circles, respectively. Reproduced with permission from ref. [84]. Copyright 2007 The American Institute of Physics.

\section{Microwave irradiation}

Material and device properties have been successfully tailored via microwave irradiation in a very recent past [81,91-92]. Microwave irradiation is a rapid and efficient heating way for highly homogenous materials processing which is eco-friendly and easy to manipulate as compared to conventional synthetic approaches. This approach has been used for large scale and cost- effective synthesis of supercapacitor electrode materials at desired temperatures up to $1500^{\circ} \mathrm{C}$ and controlled pressure ( $\leq 199 \mathrm{bar})$ at relatively short reaction time [93]. This technique has been used independently or in conjunction with other processing methods to complement them and achieve high yield innovative materials in the so-called microwave-assisted synthesis [94-102]. In a seminal research work, Newnham and co-workers investigated the microwave-matter interactions ; they reported that subjecting a material to microwave which has two vector components, namely, magnetic and electric field which induces in the material an electric polarization $\mathrm{P}\left(\mathrm{C} / \mathrm{m}^{2}\right)$ equivalent to the dipole moment $\left(\mathrm{C}^{-\mathrm{m}}\right)$ per unit volume $\left(\mathrm{m}^{-3}\right)$, hence generating thermodynamic nonequilibrium entropy mechanism [77]. The authors identified several polarization mechanisms in solids among which three major leads to loss in the microwave region, namely, space charges arising from localized electrical conduction, rotating electrical dipoles and ionic polarization associated with far-infrared vibrations [77].

\section{Characterization of Oxygen Vacancy}

Several analytical techniques have been used to characterize oxygen vacancies in transition metal oxides, namely, X-ray diffraction (XRD), Thermo-Gravimetric Analysis (TGA), Ultra- Violet Visible Spectroscopy (UV-Vis), Photoluminescence (PL) spectroscopy, Raman spectroscopy, Electron Spin Resonance (ESR), Electron Energy Loss Spectroscopy (EELS) and X-ray Photoelectron spectroscopy (XPS) [9,90,103-108]. The detailed analysis of XPS O 1s core level which consist of GAUSSIAN function deconvolution has been widely accepted among the analytical techniques used to qualitatively analyze $\mathrm{VO}$ and was carefully adopted to get more insights into $\mathrm{O} 1 \mathrm{~s}$ medium peak located at $\sim 531 \mathrm{eV}$ presented in Figure $4 \mathrm{ab}$. This peak has been ascribed to surface hydroxyl oxygen $(\mathrm{O}-\mathrm{OH})$ related to $\mathrm{O}^{2-}$ ions that are localized in the oxygen deficient regions within the ceramic lattice $[109,110]$. Moreover, Yoshida et al. successfully investigated the effect of microwave irradiation on electronic band-structure of $\mathrm{ZnO}$ via absorption and emission spectroscopy (92). The authors systematically demonstrated via PL spectroscopy that microwaves generated a new deep level defect which lowers the bandgap of $\mathrm{ZnO}$ as illustrated in Figure $4 \mathrm{~cd}$, and they assigned this defect level to zinc and oxygen plasma or to the thermal effect induced by microwave. However, particular attention should be given to the former assertion because the nonequilibrium processes resulting from thermal effect may have created oxygen vacancies which can be described via energy bandstructure as shown in Figure 4e. It is important to note that for detailed quantitative analysis of oxygen vacancy Rutherford backscattering spectroscopy and X-Ray absorption spectroscopy using synchrotron radiation are more appropriate $[111,112]$. 
Citation: Kabongo GL, Nyongombe G, Ozoemena K, Dhlamini S (2018) Microwave Irradiation Induces Oxygen Vacancy in Metal Oxides based Materials and Devices: A Review. J Nanosci Curr Res 3: 125. doi:10.4172/2572-0813.1000125

Page 4 of 13

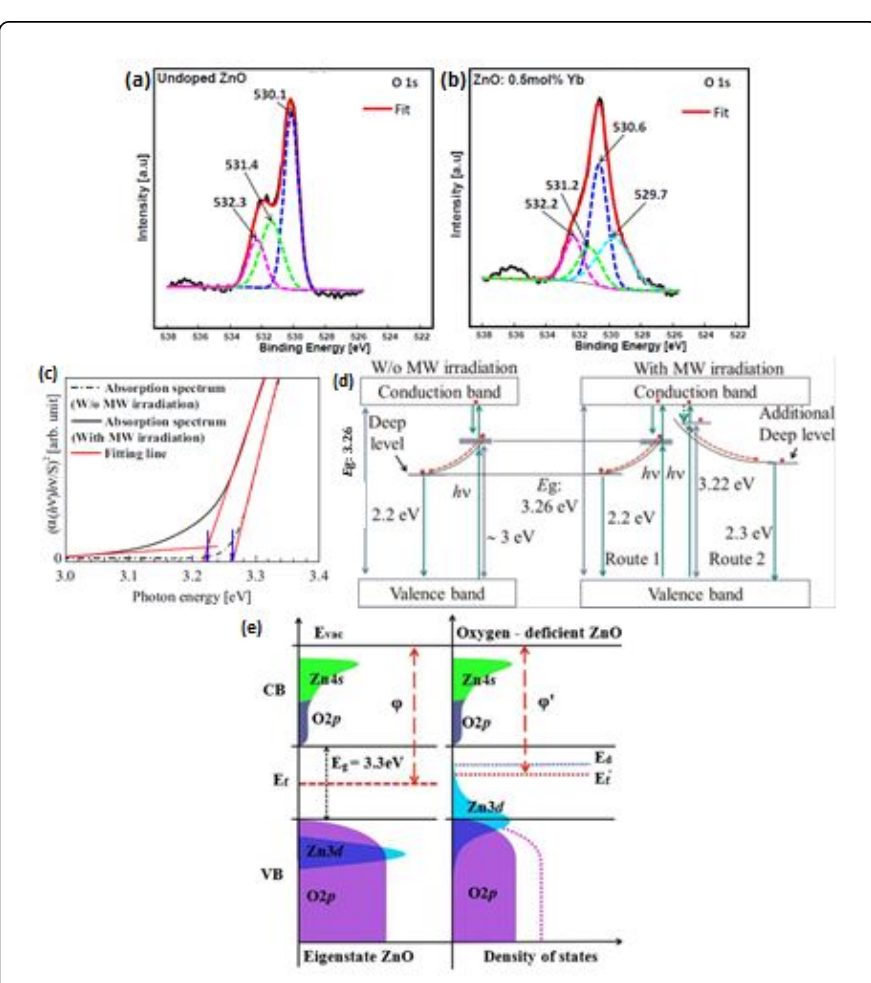

Figure 4: Deconvoluted XPS O 1s core level for (a) undoped and (b) Yb3+-doped ZnO Reproduced with permission from ref. (86). Copyright 2014 Elsevier Ltd. (c) Bandgap electronic structure and corresponding $(\mathrm{d})$ energy band diagram at room temperature for microwave (MW) irradiated and non-irradiated $\mathrm{ZnO}$ Reproduced with permission from ref. (92). Copyright 2015 Elsevier Ltd. (e) Electronic energy band structure of eigenstate and oxygen-deficient $\mathrm{ZnO}$, the pink dotted line represents the density of states of $\mathrm{O} 2 \mathrm{p}$ before the reduction, the orange bidirectional arrow indicates the work function $\left(\varphi, \varphi^{\prime}\right)$, the oxygen atoms are lost and unshared $\mathrm{Zn}$ $3 \mathrm{~d}$ states move towards the CB to form a donor level (Ed), Evac and Ef are the vacuum level and the Fermi level, respectively. Reproduced with permission from ref. (25). Copyright 2017 Elsevier Ltd.

\section{Oxygen Vacancy Enhanced Electrochemical Performances for Energy Storage}

Very recently exceptional class of materials have been uncovered, these multifunctional materials have tremendous advantages and exceptional performances in energy storage applications, namely, Layered-Double Hydroxides (LDHs), Metal Organic Frameworks (MOFs), Multishelled and nanostructured materials; among various morphologies obtained hollow-spheres are the most efficient in energy storage [113-116].

Oxygen vacancy plays an important role in tuning the physicochemical properties of these innovative materials applied in supercapacitors, lithium ions batteries, lithium sulfur batteries, sodium ion batteries, magnesium ion batteries and zinc air batteries. Some of these innovative materials were produced via microwave assisted synthesis. Copper and Nickel have been associated to produce via microwave synthesis a Hollow-sphere MOFs material for enhanced lithium battery performances [117]. Moreover, the authors revealed that the matched composition of $\mathrm{CuO} @ \mathrm{NiO}$ resulted in an efficient step-by-step lithium insertion reaction which finally contributed to the excellent electrochemical properties as presented in Figure 5. Furthermore, the core-shell architecture allowed easy lithium/electron diffusion while the volume change was accommodated in the microsphere pores of the bimetallic oxides [117].

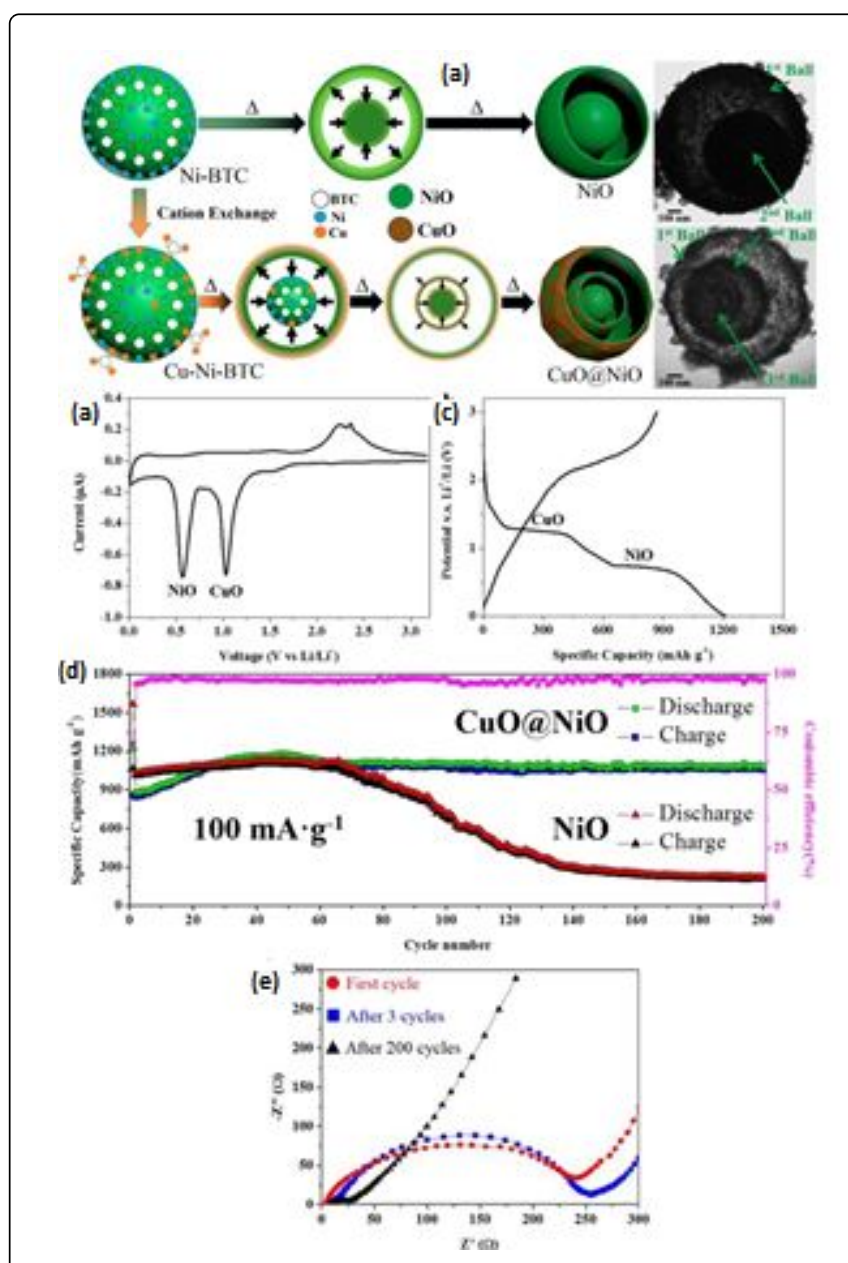

Figure 5: (a) Illustration of the cationic exchange process of metal organic framework (MOF) and its conversion to multi-layer hollow structure. Electrochemical performances of multilayer $\mathrm{CuO} @ \mathrm{NiO}$ spheres: (b) cycle voltammogram profile, (c) first cycle discharge (lithium insertion) and charge (lithium extraction) curve, (d) cycling performance at a current of $0.1{\mathrm{~A} . \mathrm{g}^{-1}}^{-1}$ and (e) Nyquist plots for the first, third and 200 cycles. Reproduced with permission from Ref. [117]. Copyright 2015 The American Chemical Society. 

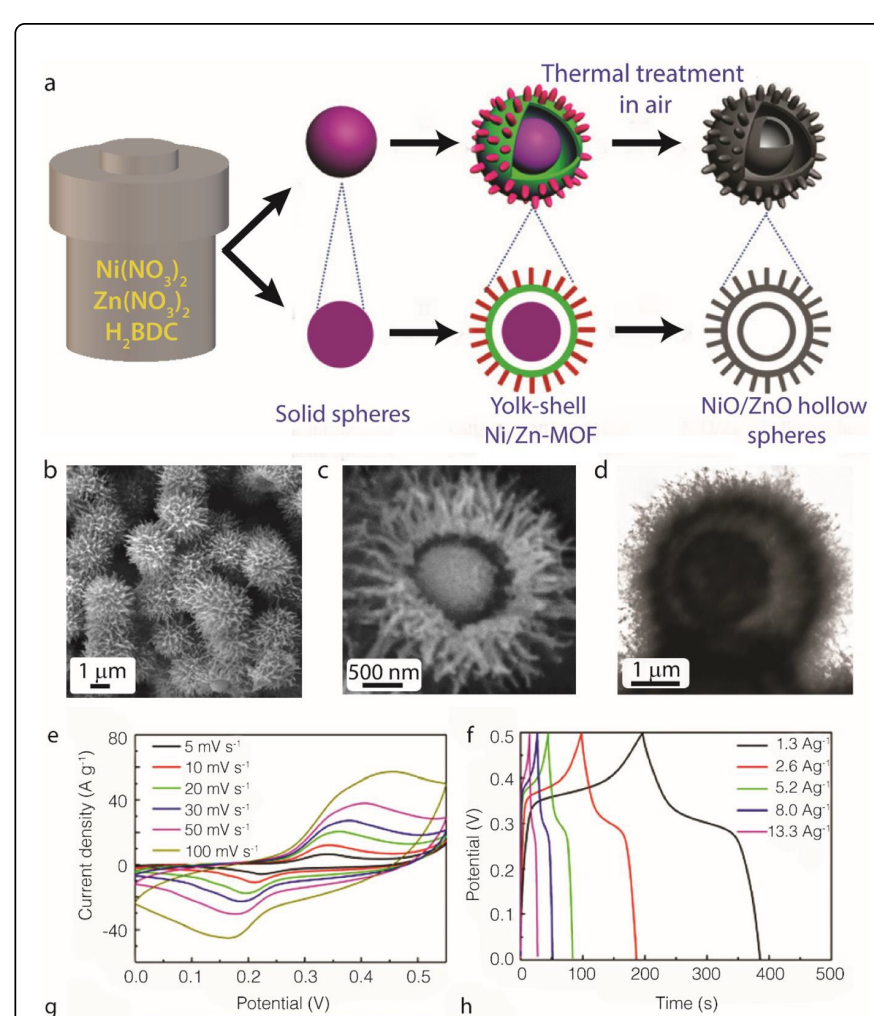

g
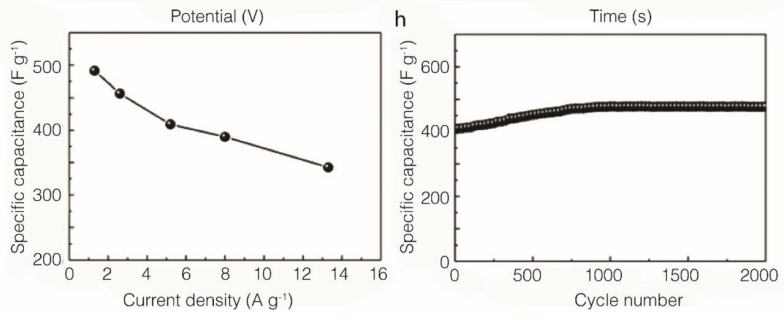

Figure 6: (a) Schematic illustration showing the formation of the yolk-shell $\mathrm{Ni} / \mathrm{Zn}-\mathrm{MOF}$ microspheres and double-shelled $\mathrm{NiO} / \mathrm{ZnO}$ hollow spheres. (b) Low- and (c) high-magnification SEM images of the Ni/Zn-MOF microspheres. (d) TEM image of the doubleshelled $\mathrm{NiO} / \mathrm{ZnO}$ hollow spheres. (e) Cyclic voltammetry (CV) and (f) galvanostatic charge-discharge (GCD) curves of the $\mathrm{NiO} / \mathrm{ZnO}$ electrode at different current densities. (g) Corresponding specific capacitance of $\mathrm{NiO} / \mathrm{ZnO}$ electrode calculated by the GCD curves. (h) Cycle performance of $\mathrm{NiO} / \mathrm{ZnO}$ electrode at a current density of 5.2 A.g ${ }^{-1}$ for 2000 cycles. Reproduced with permission from Ref. [120]. Copyright 2017.

The concept has been widely adopted and improved by several groups using different combination of TMOs and organic linkers to achieve better storage properties in supercapacitors and batteries as presented in Figures 6 and 7, respectively. In the same spirit, Li et al. produced $\mathrm{NiO} / \mathrm{ZnO}$ hierarchical double-shelled hollow spheres with exceptional cycling stability up to $117 \%$ after 2000 cycles at a current density of 5.2 A.g-1 [118]. Bruce Dunn group on the other hand remarkably demonstrated the strategic influence of oxygen vacancy on faster promotion of charge storage kinetics which makes it easy for $\mathrm{Li}$ ions intercalation and de-intercalation [9]. That leads to enhanced capacity up to $\sim 320 \mathrm{~mA} \mathrm{hg}^{-1}$ as shown in Figure 8. Teng Zhai and coworkers have exceptionally demonstrated that oxygen vacancies could enhance both conductivity and capacitance of nanorods based wearable asymmetric supercapacitor [119]. The remarkable strategy consisted of a simple hydrogenation treatment of $\mathrm{MnO} 2$ electrodes which displayed exceptional rate capability and cycling with only a moderate concentration of oxygen vacancies [119].

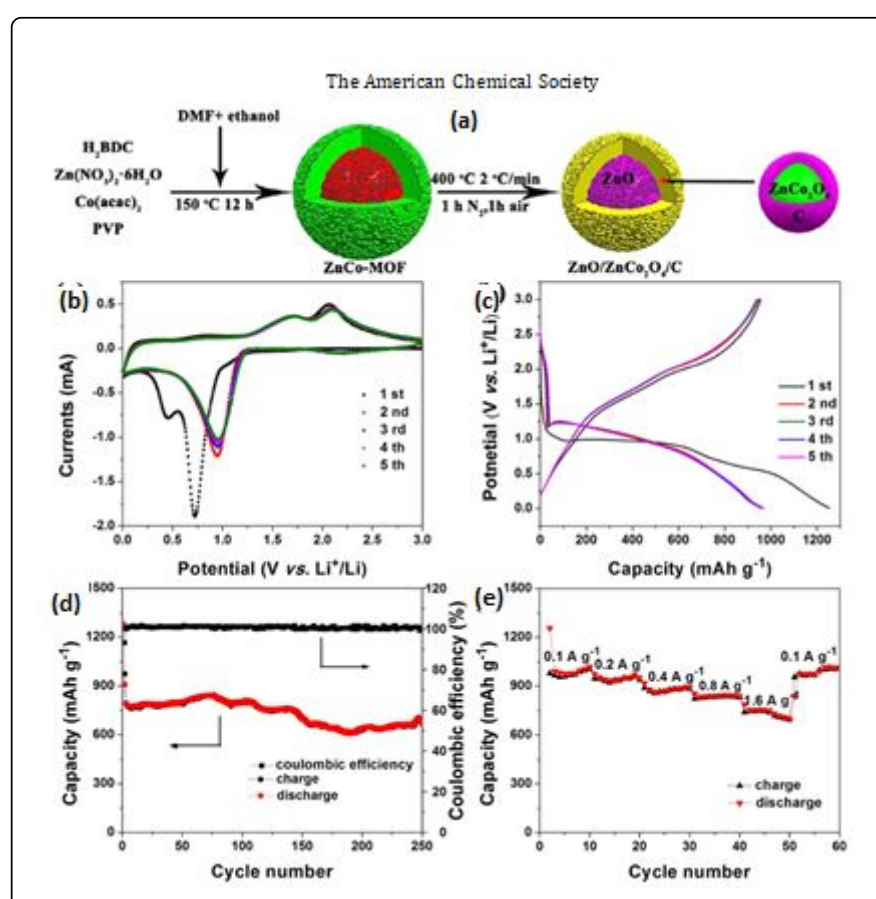

Figure 7: (a) Formation Process of Core/Shell $\mathrm{ZnO} / \mathrm{ZnCo}_{2} \mathrm{O}_{4} / \mathrm{C}$ Nanospheres (b) CV curves at a scan rate of $0.1 \mathrm{mV} \mathrm{s}^{-1}$ in the voltage range of 0.01-3.0 V. (c) Charge/discharge profiles at a current density of $0.1 \mathrm{~A}^{-\mathrm{g}^{-1}}$. (d) Cycling performance at a current density of $0.5 \mathrm{~A}^{-1}{ }^{-1}$. (e) Rate capabilities of $\mathrm{ZnO} / \mathrm{ZnCo}_{2} \mathrm{O}_{4} / \mathrm{C}$ anode. Reproduced with permission from Ref. [121] Copyright 2015 The American Chemical Society.

\section{Oxygen Vacancy Dynamic in Photovolatiac Solar Cells}

The increasing demand of clean and environmental benign energy production sources is today in the heart of public and private sector research institutes strategy development plans worldwide due to environmental concerns related to conventional energy sources based on fossil fuels and $\mathrm{CO}_{2}$ production. Researchers are currently driven to achieve innovative solutions to the betterment of mankind life through the development of pollution-free energy sources such as photovoltaic solar cells. Regardless of the type of mechanism exploited to generate and dissociate electron-hole pairs in solar cells, $\mathrm{TiO}_{2}$ has been extensively used as a counter electrode and also a hole conducting layer mainly in quantum dot and dye-sensitized solar cells [122-130]. In an astonishing investigation Su et al. [131] have for the first time experimentally demonstrated using Electron Paramagnetic Resonance (EPR) that oxygen vacancy could modulate photoelectrical conversion efficiency in a $\mathrm{TiO}_{2}$ dye-sensitized solar cell grown via hydrogenation at low temperature and mild pressure. Their exceptional findings are summarized and presented in Figure 9. The effect of oxygen vacancy on the band gap corroborates the results found in previous studies [25]. Microwave synthesis has been used to synthesize highly crystalline $\mathrm{TiO}_{2}$ with a shorter treatment time as compared to conventional heating sources when used in solar cells application 
[132]. Hence, microwave heating has been demonstrated to be more efficient than conventional heating sources such as muffle furnace, nowadays a worldwide clue. Recently Ghosh and co-workers [133] have systematically designed and fabricated via microwave a high efficient counter electrode based on CuxS and grapheme oxide for quantum dot sensitized solar cells. Owing to the challenges involved in photoanode operation, particular care was devoted to its design in order to effectively reduce the oxidized electrolyte, hereafter achieving a $6.81 \%$ record efficiency of which corresponding results are depicted in Figure 10.
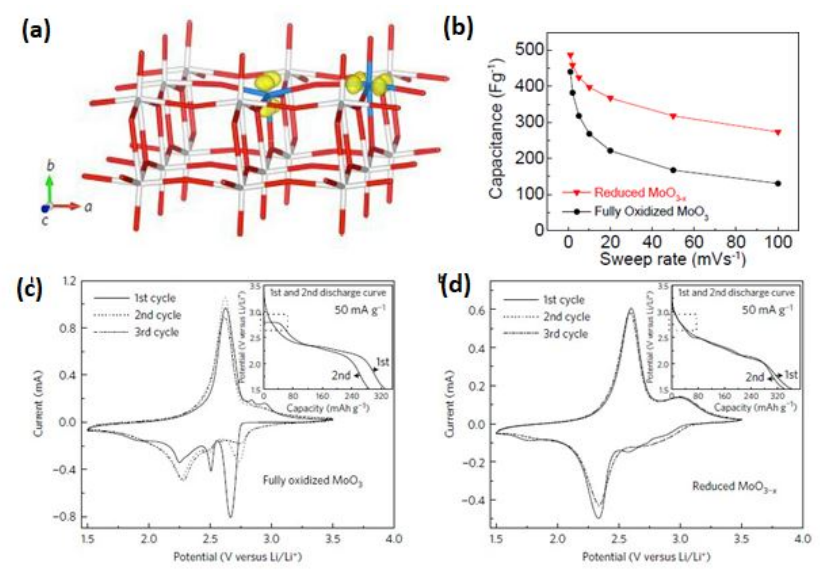

Figure 8: (a) The most stable oxygen vacancy configuration and polaron formation in $\mathrm{R}^{-\mathrm{MoO}^{3-}}{ }_{\mathrm{x}}$ calculated from DFT. The $\mathrm{Mo}^{5+}$ ions are highlighted with blue. (b) Sweep rate dependence on capacitance, (c) and (d) Cyclic voltammetry of the first three cycles at $10 \mathrm{mVs}^{-1}$ and galvanostatic discharge curves (insets, at $50 \mathrm{mA.g} \mathrm{g}^{-1}$ ) in $\mathrm{F}-\mathrm{MoO}_{3}$ and $\mathrm{R}-\mathrm{MoO}^{3-\mathrm{x}}$, respectively. Reproduced with permission from ref. (9). Copyright 2016 Macmillan Publishers Limited, part of Springer Nature.

\section{Sensor Sensitivity Derived Oxygen Vacancy}

From medical applications, namely, diseases detection and environmental protection in the mining sector, there are rooms for improvements. The growing momentum observed in the design and fabrication of electrochemical, gas and chemical sensors drive researchers and technologists to meet the agenda of the next generation of sensor devices which are sought to be flexible, highly selective and sensitive than ever. TMOs based sensors have been widely investigated for the past two decades and a lot of issues related to their practical application have been exposed and much still need to be done for easy and safe domestic usage. Among the vast majority of synthetic methods used to produce TMOs, microwave has a place of choice due to the extraordinary variety of materials morphology which also exhibit unique physic-chemical properties such as high surface area and exceptional conductivity to cite few. It should be noted that oxygen vacancy plays a critical role in materials conductivity as demonstrated by several authors $(9,25,92)$.

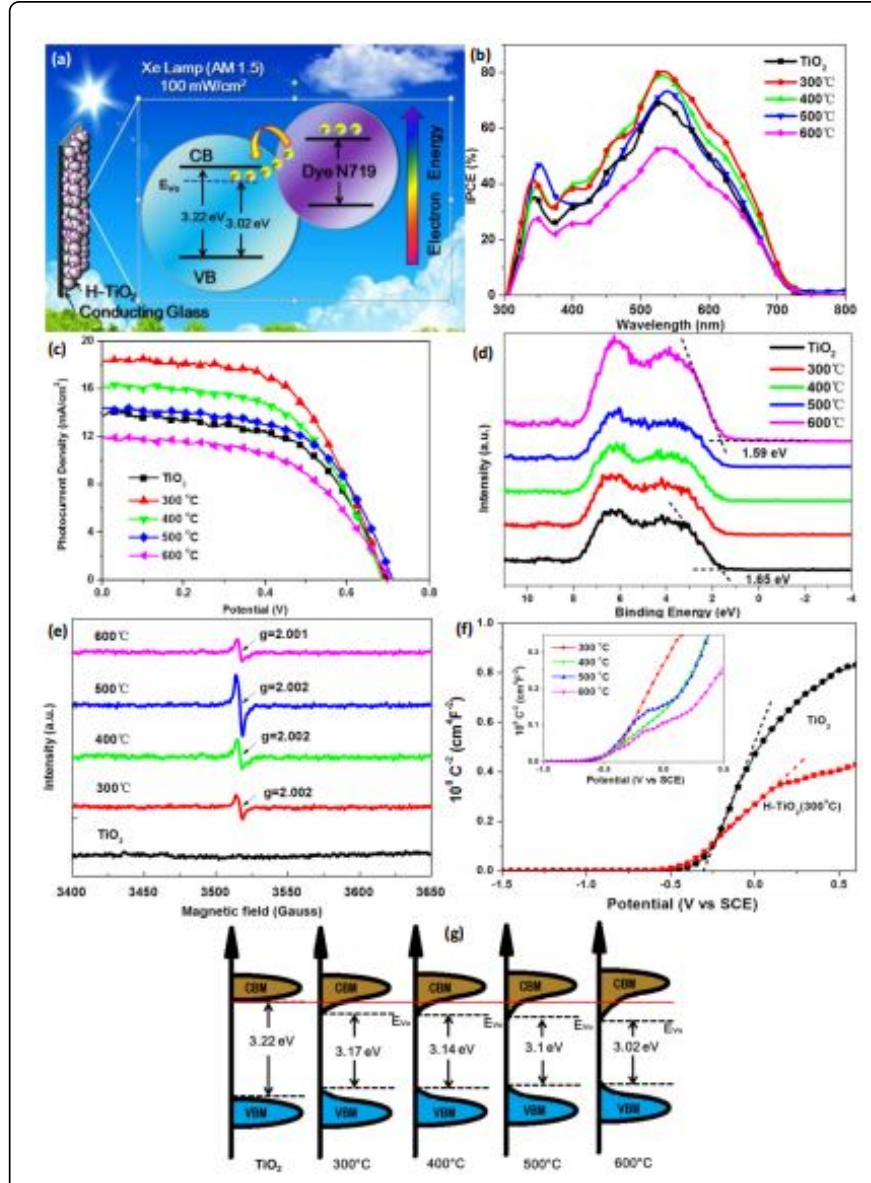

Figure 9: (a) Charge transfer mechanism for photoanode-modified DSSC based on $\mathrm{H}_{-}-\mathrm{TiO}_{2}$. (b) IPCE spectra of DSSCs based on $\mathrm{TiO}_{2}$ and $\mathrm{H}-\mathrm{TiO}_{2}$ annealed at different temperature. (c) Photocurrentphotovoltage curves under illumination (d) Valence band of $\mathrm{TiO}_{2}$ and $\mathrm{H}-\mathrm{TiO}_{2}$ treated under different temperatures. (e) EPR spectra recorded at $300 \mathrm{~K}$ for $\mathrm{TiO}_{2}, \mathrm{H}-\mathrm{TiO}_{2}$ samples. (f) Mott-Schottky plots collected in the dark for the $\mathrm{TiO}_{2}$ and the $\mathrm{H}-\mathrm{TiO}_{2}$ nanopowders. Inset Figure: Mott-Schottky plots of $\mathrm{HTiO}_{2}$ nanopowders prepared at $300^{\circ} \mathrm{C}, 400^{\circ} \mathrm{C}, 500^{\circ} \mathrm{C}$, and $600^{\circ} \mathrm{C}$, which was collected under the same conditions. (g) Schematic diagrams of electronic band structure of $\mathrm{TiO}_{2}$ and $\mathrm{H}-\mathrm{TiO}_{2}$. EVo located below the $\mathrm{TiO}_{2}$ conduction band represents the energy levels of oxygen vacancy. Reproduced with permission from ref. [131]. Copyright 2015 The American Chemical Society.

From a fundamental point of view, it is well agreed that the targeted metal oxide sensors resistance modulation is the result of a surface mechanism of oxidation-reduction reaction (ORR) involving chemisorbed oxygen with the molecules of the detected gases [134]. This implies that there exist in metal oxides based sensors a relative correlation between their sensitivity and the concentration of surface adsorbed oxygen [134]. In the same spirit, several authors have reported results in agreement of this understanding, and in particular it should be pointed out that the samples investigated in these studies were produced via microwave-assisted synthesis [89,135-139]. 

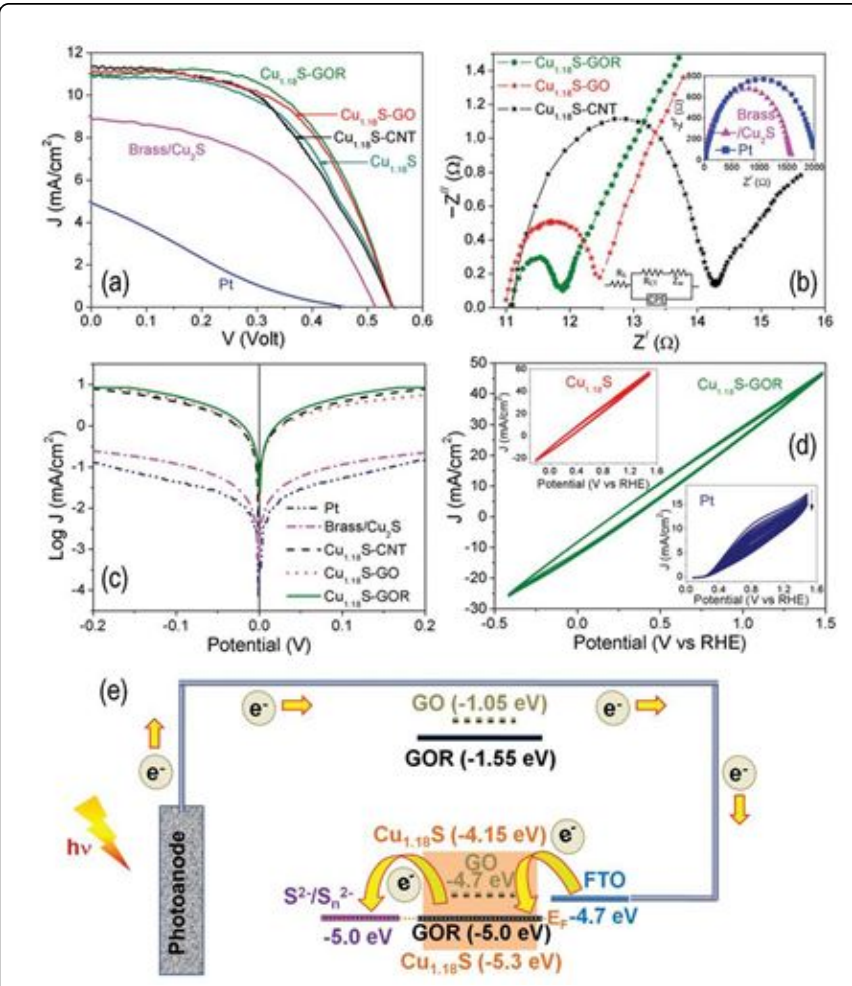

Figure 10: (a) J-V characteristics, (b) Nyquist plot and (c) Tafel polarization characteristics of $\mathrm{Pt}$, brass $/ \mathrm{Cu}_{2} \mathrm{~S}$ and $\mathrm{Cu} 1.18 \mathrm{~S}$ composites with $10 \mathrm{wt} \% \mathrm{CNT}$, GOR and GO. (d) Stability tests: 50 cycles of CV plots for Cu1.18S-GOR as the working electrode in a three electrode cell. The insets show the CV plots of the Cu1.18S working electrode for 50 cycles and Pt for 10 cycles, with an arrow showing the downward shift in current density over an increasing number of cycles. (e) Energy band diagram (not to scale) of Cu1.18S-GOR CE showing electron transfer. The energy levels of $\mathrm{GO}$ are also indicated. Reproduced with permission from ref. [133]. Copyright 2016 The Royal Society of Chemistry.

Via oxygen vacancy modulation investigated using XPS, Wang and colleagues [134] enhanced sensing performance and mechanism of hydrogenated $\mathrm{NiO}$ particles. The innovative concept investigated based on hydrogenation consisted in increasing the density of unsaturated transition metal atoms with dangling bonds on the surface, this concept was investigated elsewhere using Raman spectroscopy [104]. In the study by Wang et al., for which the sensing reaction mechanism is described and presented in the Figure 11, the XPS analysis revealed that the relative amount (\%) of oxygen vacancy increased with increase hydrogenated time as shown in Figure 11. The authors found reasonable to conclude that the sensing properties enhancement resulting from hydrogenation may originate from the increase of the relative percentage of OV and OC GAUSSIAN components in the XPS $\mathrm{O} 1 \mathrm{~s}$ core levels and also the decrease in the amount of $-\mathrm{OH}$ group [134]. Due to its role on the electronic band gap decrease and conductivity increase discussed earlier in section 3, oxygen vacancy increase could be considered as the main factor responsible for enhanced sensing activity. The response and recovery along with the sensors resistance are summarized in the Figure 12.

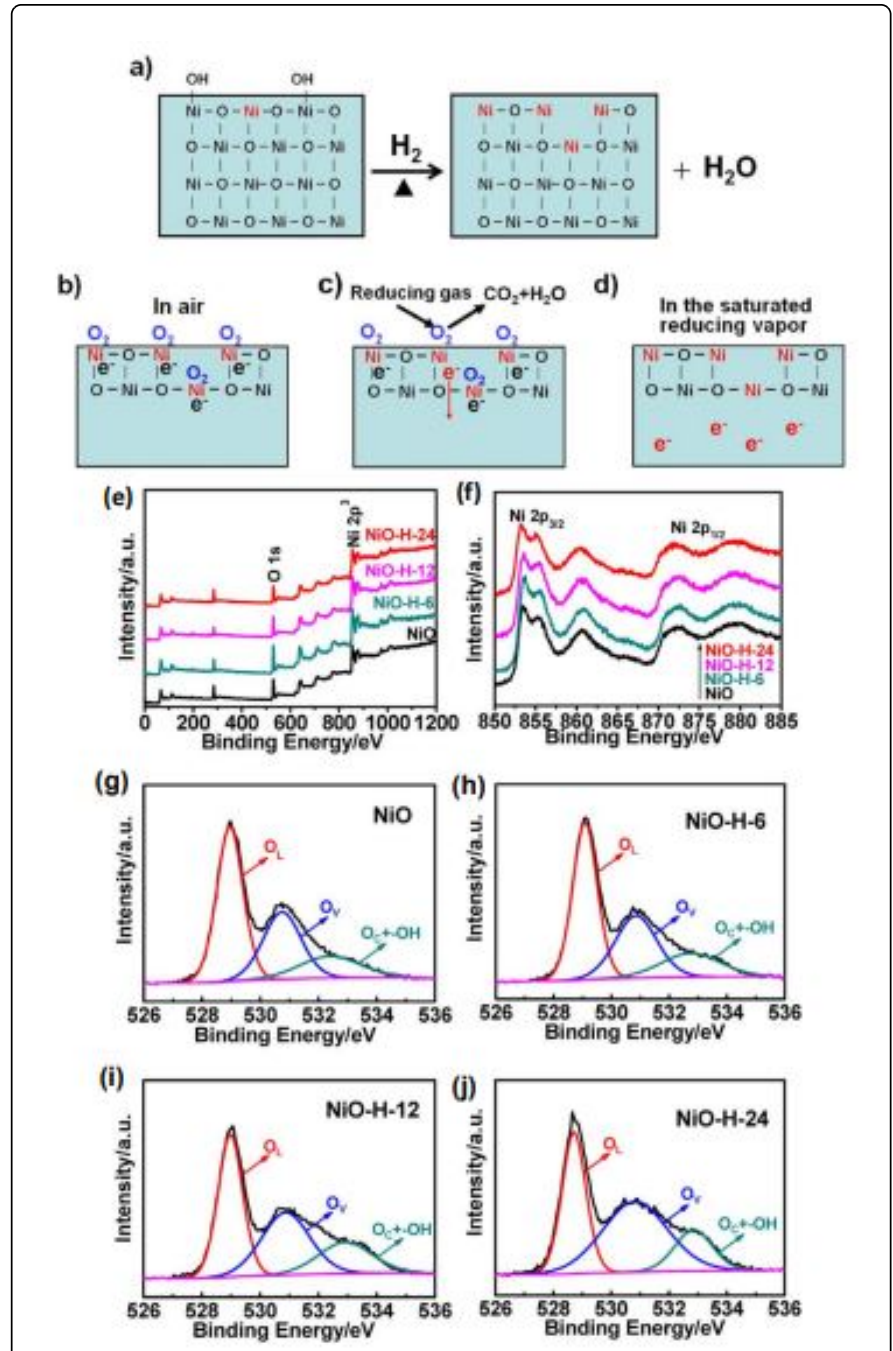

Figure 11: Schematic diagram of hydrogenation reaction of $\mathrm{NiO}$ particles. (b)-(d) Sensing reaction mechanism for $\mathrm{NiO}$ sensing materials. The letter $\mathrm{Ni}$ in red is unsaturated $\mathrm{Ni}$ atom with dangling bonds. Black e- and red e- represent the electron captured by $\mathrm{O}_{2}$ and free electron, respectively. (For interpretation of the references to colour in this figure legend, the reader is referred to the web version of this article.).The survey spectra, (e) Ni 2p3/2, 2p1/2 and (f)-(i) $\mathrm{O} 1 \mathrm{~s}$ spectra of the hydrogenated and non-hydrogenated $\mathrm{NiO}$ samples, (f) NiO, (g) NiO-H-6, (h) NiO-H-12 and (i) NiO-H-24. Reproduced with permission from ref. [134]. Copyright 2017 Elsevier Ltd.

\section{Oxygen Vacancy Modulation for Efficient Control of Field Emission and Light Emitting Devices Properties}

Since the past two decades, the display technology industry is experiencing a considerable investment of scientists and technologists to the realization of white light emitting materials and devices. It has been however demonstrated that controlling these devices calorimetric performances is closely dependent on their oxygen vacancy content [140-142]. A number of research groups have devoted their efforts to 
synthesize these light emitting materials using microwave approach [143-146].
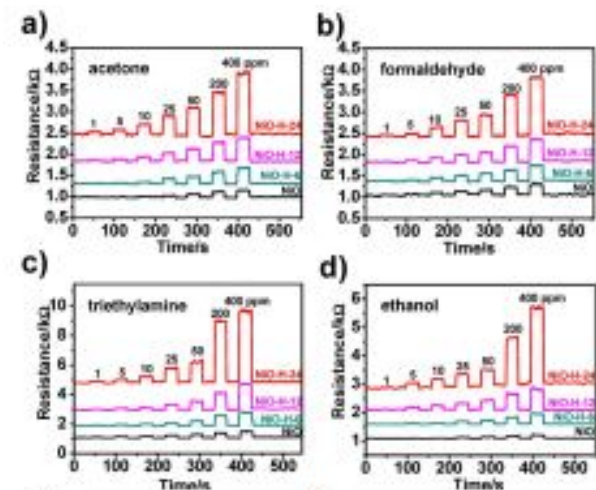

d)
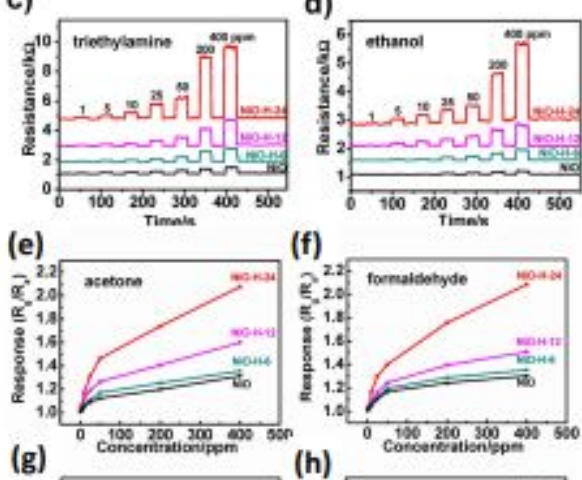

(f)
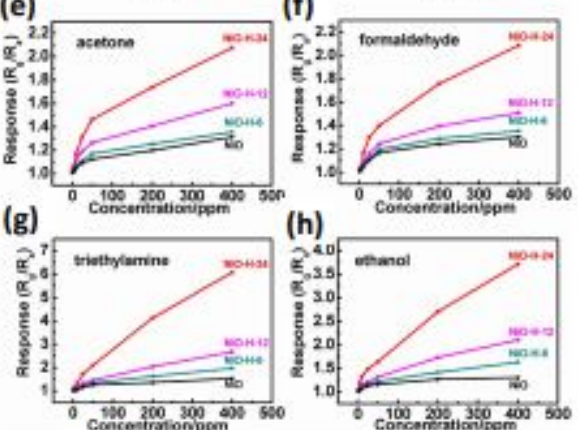

(h)

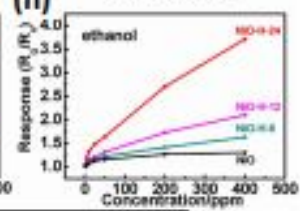

(i)

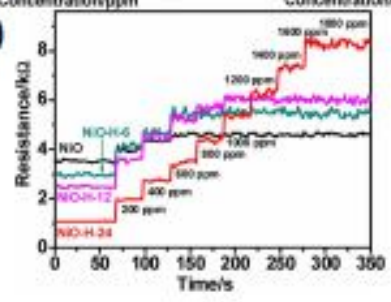

Figure 12: Response and recovery curves of the sensors based on the hydrogenated and non- hydrogenated $\mathrm{NiO}$ samples towards different concentrations of a) acetone, b) formaldehyde, c) triethylamine and d) ethanol at $350{ }^{\circ} \mathrm{C}$ and a relative humidity of $15-22 \%$. (The relative humidity values were measured at $18-22{ }^{\circ} \mathrm{C}$ ). The response curves of the sensors based on the hydrogenated and non-hydrogenated $\mathrm{NiO}$ samples towards different concentrations of (e) acetone, (f) formaldehyde, (g) triethylamine and (h) ethanol at $350{ }^{\circ} \mathrm{C}$ and a relative humidity of $15-22 \%$. (The relative humidity values were measured at $18-22^{\circ} \mathrm{C}$ ). (i) The resistances of the sensors based on the hydrogenated and nonhydrogenated $\mathrm{NiO}$ samples in air and in different concentrations of ethanol vapor at $350{ }^{\circ} \mathrm{C}$ and a relative humidity of $15 \%$. (The relative humidity value was measured at $24{ }^{\circ} \mathrm{C}$. The concentrations labeled in this figure represent the injected concentration of ethanol each time.). Reproduced with permission from ref. [134]. Copyright 2017 Elsevier Ltd.

Two years ago a thorough investigation by Zhang et al. [147] was conducted to elucidate on the role of oxygen vacancy on the persistent luminescence of a terbium doped light emitting material. The investigators focused their effort on unraveling the origin of defects involved in the enhancement of persistent luminescence for samples annealed in an oxygen-poor atmosphere. They observed via thermoluminescence spectroscopy analysis that the increase of persistent luminescence was accompanied by oxygen vacancy content increase. Moreover, a comparison of defect energy levels was conducted between their experimental findings and theoretical calculations derived from Khon-Sham levels studies by Freysoldt and co-worker [148]. They proposed a re-evaluation of the theoretical result obtained for the depth of doubly charged $\mathrm{VO} 2+$ at $0.69-0.74 \mathrm{eV}$ as compared to $1 \mathrm{eV}$ below the conduction band [147]. In the same line, $\mathrm{Xu}$ et al. [149] investigated red phosphorescence of $\mathrm{Sr}_{2} \mathrm{SnO}_{4}: \mathrm{Sm}^{3+}$ phosphor successively sintered in air and $10^{-2}$ Torr vacuum atmosphere. The later treatment option contributed to the increase in oxygen vacancies amount which according to authors acted as the sensitizer and electron traps for effective energy transfer from the host matrix $\mathrm{Sr} 2 \mathrm{SnO} 4$ to the dopant $\mathrm{Sm} 3+$. The findings of their study are summarized in Figure 13. Finally, remarkable enhanced phosphorescence properties were achieved by the authors after vacuum sintering process [149].
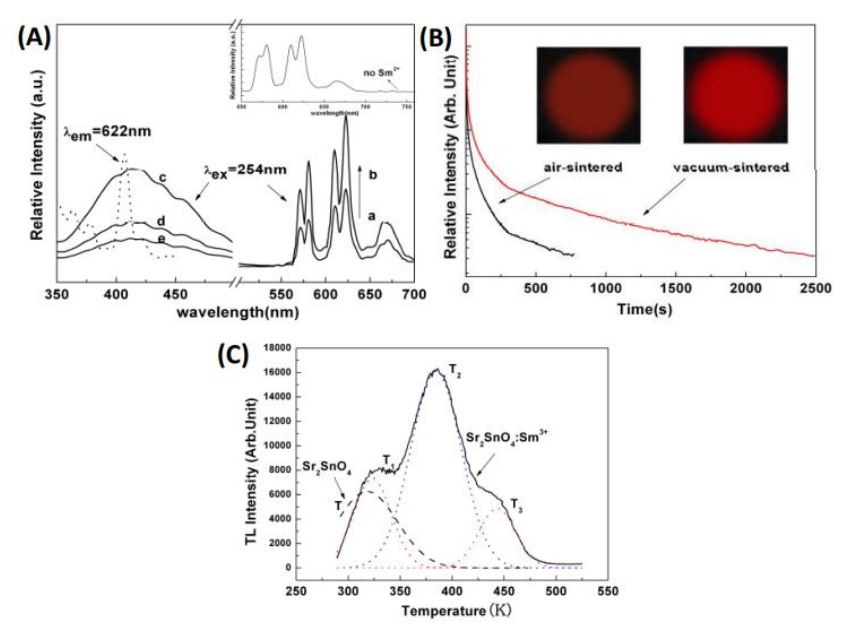

Figure 13: (A) Emission $(\lambda e x=254 \mathrm{~nm})$ and excitation $(\lambda e m=622$ nm) spectra of $\mathrm{Sr}_{2} \mathrm{SnO}_{4}$ and $\mathrm{Sr}_{2} \mathrm{SnO}_{4}: \mathrm{Sm}^{3+}$. (a) is the emission spectrum of the air-sintered $\mathrm{Sr}_{2} \mathrm{SnO}_{4}: \mathrm{Sm}^{3+}$. (b), (d) and inset are the emission spectra of $\mathrm{Sr}_{2} \mathrm{SnO}_{4}: \mathrm{Sm}^{3+}$ sintered in vacuum. (c) and (e) are the emission spectra of $\mathrm{Sr}_{2} \mathrm{SnO}_{4}$ sintered in vacuum and air, respectively. Left dash curve is the excitation spectrum of $\mathrm{Sr}_{2} \mathrm{SnO}_{4}$ : $\mathrm{Sm}^{3+}$ sintered in vacuum. (B) Afterglow decay curves of $\mathrm{Sr}_{2} \mathrm{SnO}_{4}$ : $\mathrm{Sm}^{3+}$ sintered in air and vacuum. Inset: long afterglow photographs of $\mathrm{Sr}_{2} \mathrm{SnO}_{4}: \mathrm{Sm}^{3+}$ sintered in air and vacuum. The photographs were taken in the darkroom for $1 \mathrm{~min}$ after the removal of the $254-\mathrm{nm}$ ultraviolet lamp. (C) Thermoluminescence glow curves of the vacuum-sintered $\mathrm{Sr}_{2} \mathrm{SnO}_{4}$ and $\mathrm{Sr}_{2} \mathrm{SnO}_{4}$ : $\mathrm{Sm}^{3+}$. Reproduced with permission from ref. (149). Copyright 2010 The Optical Society of America.

In a very recent research work, Ai-Zhen Liao et al. [150] successfully increased field emission properties of a device based on $\alpha-\mathrm{Fe}_{2} \mathrm{O}_{3}$ nanorod arrays via conductivity increase and work function decrease through polaronic hopping mechanism owing to oxygen vacancy. The significant findings of the study among which band-structure modification similarly reported by earlier authors are summarized in the Figure 14 shown below [25,92]. Unambiguously the investigation revealed according to the authors that oxygen deficient HNAs were potential candidates for nanoelectronic applications and more 
precisely in cutting-edge field of electron emitter devices and flat panel displays [150].

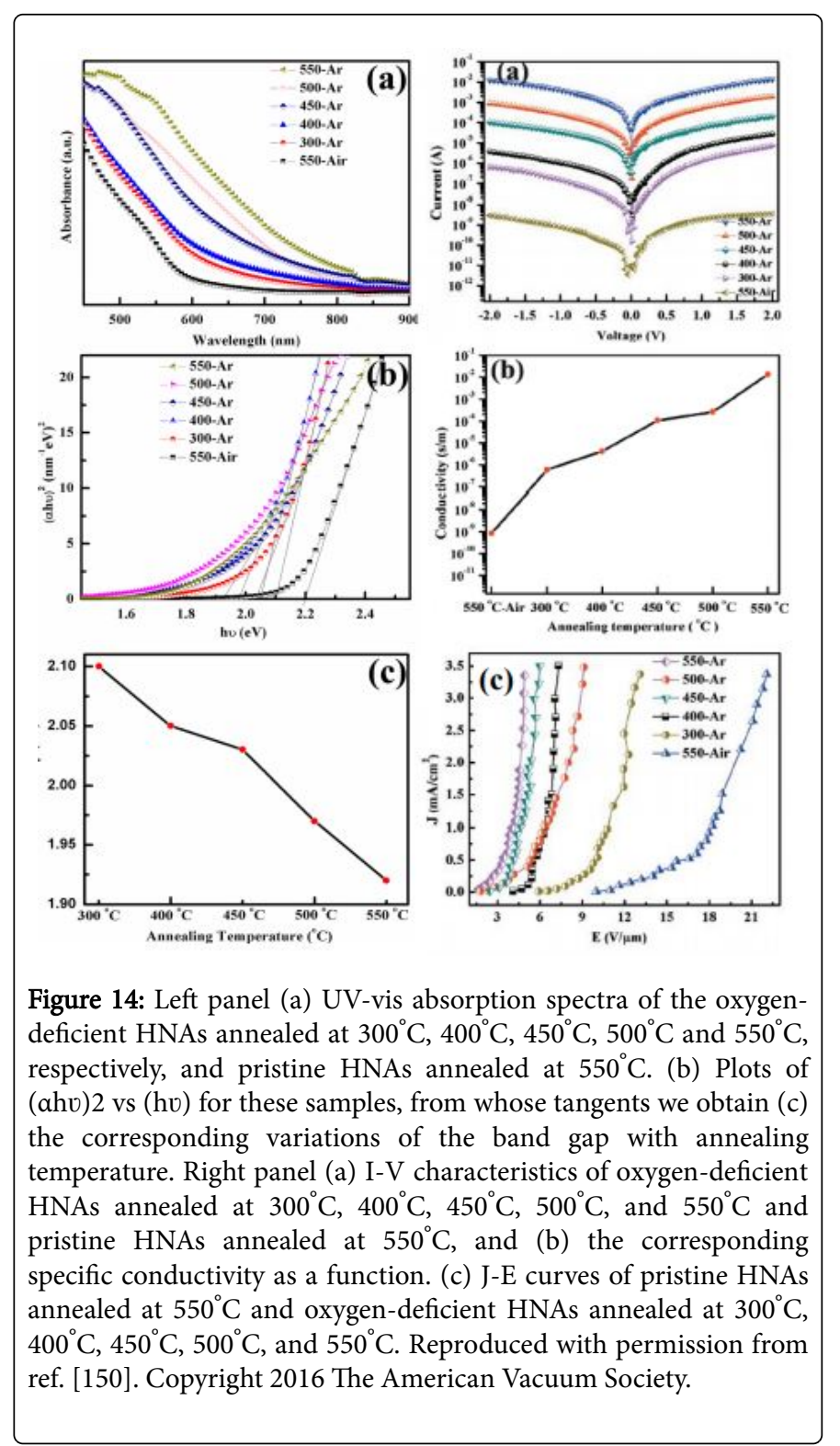

\section{Conclusion}

This mini-review paper provides an overview of microwave irradiation tuning of oxygen vacancy and its role in tailoring materials properties. The key performances of energy storage, sensor and light emitting materials have been widely assigned to oxygen vacancy. Various approaches have been reported to account for oxygen vacancy control among which microwave irradiation is one of the most accessible and cost effective. It has been demonstrated that at some extent oxygen vacancy increase is responsible of the p-type conductivity observed in these materials and plays a considerable role in the exceptional performances documented in the literature. Due to thermodynamic nonequilibium processes that occur during microwave irradiation which contribute to the formation of oxygen deficient sites in the lattice structure, microwave treatment should be considered as an effective approach to boost electrochemical, sensing and optical properties via protonic conductivity enhancement among others. A consistent observation of the microwave effect on the band structure modification has been established, which in most cases resulted in band-gap decrease due to the creation of defects levels above the valence band highest unoccupied level and below the conduction band lowest occupied level. These lead to the overall agreement that oxygen vacancy enhance electronic conductivity and carriers mobility in most materials and devices leading to easy transport of injected electrons through oxygen deficient sites. Further thermodynamic nonequilibrium processes can be studied from other electromagnetic radiation sources such as UV light to achieve same or better results. However, in devices where exciton dissociation and recombination processes occur, challenging control of interfacial oxygen vacancy is required in order not to degrade their physicochemical performances. Finally, the attention of the reader should also be directed to the importance of XPS analysis which is one of the most accessible analytical techniques needed for effective oxygen vacancy characterization.

\section{Acknowledgements}

One of the authors (G.L.) gratefully acknowledges the University of Witwatersrand fianacial support via the URC postdoctoral fellowship (\#A0055687).

\section{References}

1. Cliffe MJ, Wan W, Zou XD, Chater PA, Kleppe AK, et al. (2014) Correlated defect nanoregions in a metal- organic framework. Nat Commun 5: 4176.

2. Taylor J, Dekura S, Ikeda R, Kitagawa H (2015) Defect control to enhance proton conductivity in a metal-organic framework. Chem Mater 27: 2286-2289.

3. Fu J, Hassan FM, Zhong C, Lu J, Liu H, et al. (2017) Defect engineering of chalcogen-tailored oxygen electrocatalysts for rechargeable quasi-solidstate zinc-air batteries. Adv Mater 29: 1702526.

4. Pan X, Min-Quan Y, Fu X, Zhang N, Yi-Jun X (2013) Defective TiO2 with oxygen vacancies: synthesis, properties and photocatalytic applications. Nanoscale 5: 3601.

5. Ting Su, Yang Y, Yong Na, Ruiqing Fan, Liang Li, et al. (2015) An insight into the role of oxygen vacancy in hydrogenated Tio2 nanocrystals in the performance of dye-sensitized solar cells. ACS Appl Mater Interfaces 7: 3754-3763.

6. Zhang L, Wang S, Chao Lu (2015) Detection of oxygen vacancies in oxides by defect-dependent cataluminescence. Anal Chem 87: 7313-7320.

7. Cheng F, Zhang T, Zhang Y, Du J, Han X, et al. (2013) Enhancing electrocatalytic oxygen reduction on $\mathrm{mno} 2$ with vacancies. Angew Chem Int Ed 52: 2474 -2477.

8. Veal BW, Kim SK, Zapol P, Iddir H, Baldo PM, et al. (2016) Interfacial control of oxygen vacancy doping and electrical conduction in thin film oxide heterostructures. Nat Commun 7.

9. Kim HS, Cook JB, Lin H, Ko JS, Tolbert SH, et al. (2017) Oxygen vacancies enhance pseudocapacitive charge storage properties of MoO3x. Nat Mater 16: 454-460.

10. Ganduglia-Pirovano MV, Hofmann A, Sauer J (2007) Oxygen vacancies in transition metal and rare earth oxides: current state of understanding and remaining challenges. Surf Sci Rep 62: 219-270.

11. Janotti A, Van de Walle CG (2007) Native point defects in ZnO. Phys Rev B 76: 165202.

12. Erhart P, Albe K, Klein A (2006) First-principles study of intrinsic point defects in $\mathrm{ZnO}$ : role of band structure, volume relaxation, and finite-size effects. Phys Rev B 73: 205203. 
13. Ai-Zhen L, Jian-Biao C, Cheng-Wei W, Xiao-Feng S, Li Y, et al. (2016) Enhanced field emission properties from oxygen-deficient a-Fe2O3 nanorod arrays. J Vac Sci Technol B 34: 021803.

14. Wang M, Wang Y, Liu J, Pei C, Liu B, et al. (2017) Enhanced sensing performance and sensing mechanism of hydrogenated $\mathrm{NiO}$ particles. Sensors Actuators B 250: 208-214.

15. Fan YH, Ho CY, Chang YJ (2017) Enhancement of dye-sensitized solar cells efficiency using mixed-phase $\mathrm{TiO} 2$ nanoparticles as photoanode. Scanning.

16. Ghosh D, Halder G, Sahasrabudhe A, Bhattacharyya S (2016) A microwave synthesized CuxS and graphene oxide nanoribbon composite as a highly efficient counter electrode for quantum dot sensitized solar cells. Nanoscale 8: 10632.

17. Karppinen M, Fjellvåg H, Konno T, Morita Y, Motohashi T, et al. (2004) Evidence for Oxygen Vacancies in Misfit-Layered Calcium Cobalt Oxide, [CoCa2O3] qCoO2. Chem Mater 16: 2790-2793.

18. Ahmad R, Tripathy N, Ahn MS, Bhat KS, Mahmoudi T, et al. (2017) Highly efficient non-enzymatic glucose sensor based on $\mathrm{CuO}$ modified vertically-grown $\mathrm{ZnO}$ nanorods on electrode. Sci Rep 7: 5715.

19. Huygh S, Bogaerts A, Neyts EC (2016) How oxygen vacancies activate $\mathrm{CO} 2$ dissociation on $\mathrm{TiO} 2$ anatase (001). J Phys Chem C 120: 21659-21669.

20. Stefik M, Heiligtag FJ, Niederberger M, Gratzel M (2013) Improved Nonaqueous Synthesis of TiO2 for Dye-Sensitized Solar Cells. ACS Nano 7: 8981-8989.

21. Carrettin S, Hao Y, Aguilar-Guerrero V, Gates BC, Trasobares S, et al. (2007) Increasing the Number of Oxygen Vacancies on TiO2 by Doping with Iron Increases the Activity of Supported Gold for CO Oxidation. Chem Eur J 13: 7771-7779.

22. Zhang J, Zhao Z, Wang X, Yu T, Guan J, et al. (2010) Increasing the oxygen vacancy density on the $\mathrm{TiO} 2$ surface by la-doping for dyesensitized solar cells. J Phys Chem C 114: 18396-18400.

23. Park S, Ahn HS, Lee CK, Kim H, Jin H, et al. (2008) Interaction and ordering of vacancy defects in NiO. Phys Rev B 77: 134103.

24. Brahma S, Liu CP, Shivashankar SA (2017) Microwave irradiation assisted, one pot synthesis of simple and complex metal oxide nanoparticles: a general approach. J Phys D Appl Phys 50: 40LT03.

25. Su XF, Chen JB, He RM, Li Y, Wang J, et al. (2017) The preparation of oxygen-deficient $\mathrm{ZnO}$ nanorod arrays and their enhanced field emission. Mater Sci Semicond Process 67: 55-61.

26. Simo A, Kaviyarasu K, Mwakikunga B, Madjoe R, Gibaudv A, et al. (2017) Phase transition study in strongly correlated VO2 based sensing systems transition study in strongly correlated $\mathrm{VO} 2$ based sensing systems. J Electron Spectros Relat Phenomena 216: 23-32.

27. Qi X, Zheng W, Li X, He G (2016) Multishelled NiO hollow microspheres for high- performance supercapacitors with ultrahigh energy density and robust cycle life. Sci Rep 6: 33241.

28. Ren H, Yu R, Wang J, Jin Q, Yang M, et al. (2014) Multishelled TiO2 hollow microspheres as anodes with superior reversible capacity for lithium ion batteries. Nano Lett 14: 6679-6684.

29. Wang J, Tang H, Ren H, Yu R, Qi J, et al. (2014) pH-Regulated synthesis of multi-shelled manganese oxide hollow microspheres as supercapacitor electrodes using carbonaceous microspheres as templates. Adv Sci 1: 1400011.

30. Xu S, Hessel CM, Ren H, Yu R, Jin Q, et al. (2014) $\alpha$-Fe2O3 multi- shelled hollow microspheres for lithium ion battery anodes with superior capacity and charge retention. Energy Environ Sci 7: 632.

31. Sun C, Wang Y, Zou J, Smith SC (2011) A formation mechanism of oxygen vacancies in a $\mathrm{MnO} 2$ monolayer: a DFT + U study. Phys Chem Chem Phys 13: 11325-11328.

32. Teresa $\mathrm{OH}$ (2017) A study on an oxygen vacancy and conductivity of oxide thin films deposited by rf magnetron sputtering and annealed in a vacuum. Trans Electr Electron Mater 18: 21.
33. Li N, Du K, Liu G, Xie Y, Zhou G, et al. (2013) Effects of oxygen vacancies on the electrochemical performance of tin oxide. J Mater Chem A 1: 1536.

34. Sushko PV, Rosso KM, Zhang JG, Liu J, Sushko ML (2013) Oxygen vacancies and ordering of d-levels control voltage suppression in oxide cathodes: the case of spinel LiNi0.5Mn1.5O4- $\delta$. Adv Funct Mater 23: 5530-5535.

35. Gaggiotti G (1994) Surface chemistry of tin oxide based gas sensors. I Appl Phys 76: 4467.

36. Wu QH, Thissen A, Jaegermann W, Liu ML (2004) Photoelectron spectroscopy study of oxygen vacancy on vanadium oxides surface. Appl Surf Sci 236: 473.

37. Lambrecht W, Djafari-Rouhani B, Vennik J (1981) Electronic structure of the vanadyl oxygen vacancy in $\mathrm{V} 2 \mathrm{O} 5$ : periodic vacancy single layer model. Solid State Commun 39: 257.

38. Tit N (1993) Electronic-structure of a single oxygen vacancy in rutile TiO2. Nuovo Cimento 15: 1405.

39. Bredow T, Pacchioni G (2002) Electronic structure of an isolated oxygen vacancy at the TiO2(110) surface. Chem Phys Lett 355: 417.

40. Wu X, Selloni A, Lazzeri M, Nayak SK (2003) Oxygen vacancy mediated adsorption and reactions of molecular oxygen on the $\mathrm{TiO} 2(110)$ surface. Phys Rev B 68: 241402.

41. Hofmann SJ, Clark M, Oppel I, Hahndorf I (2002) Hydrogen adsorption on the tetragonal $\mathrm{ZrO} 2(101)$ surface: a theoretical study of an important catalytic reactant. Phys Chem Chem Phys 4: 3500.

42. Safonov AA, Bagaturyants AA, Korkin AA (2003) Oxygen vacancies in tetragonal $\mathrm{ZrO} 2: \mathrm{Ab}$ initio embedded cluster calculations. Microelectron Eng 69: 629.

43. Sayle TXT, Parker SC, Catlow CRA (1994) The role of oxygen vacancies on ceria surfaces in the oxidation of carbon-monoxide. Surf Sci 316: 329.

44. Jiang Y, Adams JB, van Schilfgaarde M, Sharma R, Crozier PA (2005) Theoretical study of environmental dependence of oxygen vacancy formation in CeO2. Appl Phys Lett 87: 141917.

45. Skorodumova NV, Simak SI, Lundqvist BI, Abrikosov IA, Johansson B (2002) Quantum origin of the oxygen storage capability of ceria. Phys Rev Lett 89: 166601.

46. Nolan M, Fearon JE, Watson GW (2006) Oxygen vacancy formation and migration in ceria. Solid State Ion 177: 3069.

47. Mori-Sanchez P, Recio JM, Silvi B, Sousa C, Pendas AM, et al. (2002) Rigorous characterization of oxygen vacancies in ionic oxides. Phys Rev B 66: 075103.

48. Bredow T, Gerson AR (2000) Effect of exchange and correlation on bulk properties of $\mathrm{MgO}, \mathrm{NiO}$, and CoO. Phys Rev B 61: 5194.

49. Kumar V, Swart HC, Ntwaeaborwa OM, Kroon RE, Terblans JJ, et al. (2013) Origin of the red emission in zinc oxide nanophosphors. Materials Letters 101: 57-60.

50. Pandey A, Rai VK, Kumar V, Swart HC (2015) Upconversion based temperature sensing ability of Er3+-Yb3+ codoped SrWO4: an optical heating phosphor. "Sens Actuators B Chem 209: 352-358.

51. Som S, Kunti AK, Kumar V, Kumar V, Dutta S, et al. (2014) Defect correlated fluorescent quenching and electron phonon coupling in the spectral transition of $\mathrm{Eu} 3+$ in $\mathrm{CaTiO} 3$ for red emission in display application. J Appl Phys 115: 193101.

52. Ngom BD, Mpahane T, Manyala N, Nemraoui O, Buttner U, et al. (2009) Structural and optical properties of nano-structured tungsten-doped $\mathrm{ZnO}$ thin films grown by pulsed laser deposition. Appl Surf Sci 2557: 4153-4158.

53. Magdalane CM, Kaviyarasu K, Vijaya JJ, Siddhardha B, Jeyaraj B, et al. (2018) Evaluation on the heterostructured $\mathrm{CeO} 2 / \mathrm{Y} 2 \mathrm{O} 3$ binary metal oxide nanocomposites for UV/Vis light induced photocatalytic degradation of Rhodamine - B dye for textile engineering application. J Alloys Compd 727: 1324-1337.

54. Kabongo GL, Mhlongo GH, Mothudi BM, Mbule PS, Hillie KT, et al. (2017) Structural, photoluminescence and XPS properties of Tm3+ ions in $\mathrm{ZnO}$ nanostructures. J Lum 187: 141-153. 
55. Yaghi OM, O’ Keeffe M, Ockwig NW, Chae HK, Eddaoudi M, et al. (2003) Reticular synthesis and the design of new materials. Nature 423: 705-714.

56. Dolgopolova EA, Brandt AJ, Ejegbavwo OA, Duke AS, Maddumapatabandi TD, et al. (2017) Electronic properties of bimetallic metal-organic frameworks (MOFs): tailoring the density of electronic states through mof modularity. J Am Chem Soc 139: 5201-5209.

57. Guan BY, Kushima A, Yu L, Li S, Li J, et al. (2017) Coordination polymers derived general synthesis of multishelled mixed metal-oxide particles for hybrid supercapacitors. Adv Mater 29: 1605902.

58. Hu H, Guan B, Xia B, Wen X (2015) Designed formation of Co3O4/ NiCo2O4 double-shelled nanocages with enhanced pseudocapacitive and electrocatalytic properties. J Am Chem Soc 137: 5590-5595.

59. Zhang G, Wen X (2014) General synthesis of multi-shelled mixed metal oxide hollow spheres with superior lithium storage properties. Angew Chem Int Ed 53: 9041-9044.

60. Li H, Ma H, Yang M, Wang B, Shao H, et al. (2017) Highly controlled synthesis of multi-shelled $\mathrm{NiO}$ hollow microspheres for enhanced lithium storage properties. Mater Res Bull 87: 224-229.

61. Jiang Z, Li Z, Qin Z, Sun H, Jiao X et al. (2013) LDH nanocages synthesized with MOF templates and their high performance as supercapacitors. Nanoscale 5: 11770 .

62. Li X, Wang L, Shi J, Du N, He G (2016) Multishelled nickel-cobalt oxide hollow microspheres with optimized compositions and shell porosity for high-performance pseudocapacitors. ACS Appl Mater Interfaces 8: 17276-17283.

63. Li R, Hu Z, Shao X, Cheng P, Li S, et al. (2016) Large scale synthesis of NiCo layered double hydroxides for superior asymmetric electrochemical capacitor. Sci Rep 6: 18737.

64. Lu XF, Gu LF, Wang JW, Wu JX, Liao PQ, et al. (2017) Bimetal-organic framework derived $\mathrm{CoFe} 2 \mathrm{O} 4 / \mathrm{C}$ porous hybrid nanorod arrays as highperformance electrocatalysts for oxygen evolution reaction. Adv Mater 29: 1604437.

65. Qi H, Wenji Z, Li X, He G (2016) Multishelled NiO hollow microspheres for high- performance supercapacitors with ultrahigh energy density and robust cycle life. Sci Rep 6: 33241.

66. Kabongo GL, Mhlongo GH, Mothudi BH, Mbule PS, Hillie KT, et al. (2017) Structural, photoluminescence and XPS properties of Tm3+ ions in $\mathrm{ZnO}$ nanostructures. J Lum 187: 141-153.

67. Fell CR, Qian D, Carroll KJ, Chi M, Jones JL, et al. (2013) Correlation between oxygen vacancy, microstrain, and cation distribution in lithiumexcess layered oxides during the first electrochemical cycle. Chem Mater 25: 1621-1629.

68. Kaur J, Kumar P, Sathiaraj TS, Thangaraj R (2013) Structural, optical and fluorescence properties of wet chemically synthesized $\mathrm{ZnO}: \mathrm{Pd} 2+$ nanocrystals. Int Nano Lett 3: 1-7.

69. Raju K, Nkosi FP, Viswanathan E, Mathe MK, Damodaran K, et al. (2016) Microwave-enhanced electrochemical cycling performance of the LiNi0.2Mn1.8O4 spinel cathode material at elevated temperature. Phys Chem Chem Phys 18: 13074-13083.

70. Kebede MA, Yannopoulos SN, Sygellou L, Ozoemena KI (2017) Highvoltage $\mathrm{LiNi} 0.5 \mathrm{Mn} 1.5 \mathrm{O} 4-\delta$ spinel material synthesized by microwaveassisted thermo-polymerization: some insights into the microwaveenhancing physico-chemistry. J Electrochem Soc 164: A3259-A3265.

71. Jafta CJ, Mathe MK, Manyala N, Roos WD, Ozoemena KI (2013) Microwave-assisted synthesis of high-voltage nanostructured LiMn1.5Ni0.5O4 spinel: tuning the Mn3+ content and electrochemical performance. ACS Appl Mater Interfaces 5: 7592-7598.

72. Zhu YJ, Chen F (2014) Microwave-assisted preparation of inorganic nanostructures in liquid phase. Chem Rev 114: 6462-6555.

73. Sun J, Wang W, Yue Q (2016) Review on microwave-matter interaction fundamentals and efficient microwave-associated heating strategies. Materials 9: 231.

74. Jacob J, Chia LH (1995) Thermal and non-thermal interaction of microwave radiation with materials. J Mat Sci 30: 5321-5327.
75. Newnham RE, Jang SJ, Xu M, Jones F (1991) Fundamental interaction mechanisms between microwaves and matter. Ceramic Transactions 21 Proceedings of the symposium on microwave theory and application in materials processing annual meeting of the american ceramic society.

76. Pfau A, Schierbaum KD (1994) The electronic structure of stoichiometric and reduced $\mathrm{CeO} 2$ surfaces: an XPS, UPS and HREELS study. Surface Science 321: 71-80.

77. Horikoshi S, Minatodani Y, Tsutsumi H, Uchida H, Abe M (2013) Influence of lattice distortion and oxygen vacancies on the UV-driven/ microwave assisted $\mathrm{TiO} 2$ photocatalysis. J Photochem Photobiol A: Chem 265: 20-28.

78. Janotti A, Van de Walle CG (2009) Fundamentals of zinc oxide as a Semiconductor. Rep Prog Phys 72: 126501.

79. Khan ME, Khan MM, Cho MH (2017) Ce3+-ion, surface oxygen vacancy, and visible light-induced photocatalytic dye degradation and photocapacitive performance of $\mathrm{CeO} 2-$ graphene nanostructures. Scientific Reports. 7: 5928.

80. Su D, Xie X, Dou S, Wang G (2014) CuO single crystal with exposed $\{001\}$ facets - A highly efficient material for gas sensing and Li-ion battery applications. Scientific Reports 4: 5753.

81. Golbamaki N, Rasulev B, Cassano A, Robinson RLM, Benfenati E, et al. (2015) Genotoxicity of metal oxide nanomaterials: review of recent data and discussion of possible mechanisms. Nanoscale 7: 2154-2198.

82. Li Y, Shen W (2014) Morphology-dependent nanocatalysts: rod-shaped oxides. Chem Soc Rev 43: 1543-1574.

83. Liu B, Yang H, Wei A, Zhao H, Ning L, et al. (2015) Superior photocatalytic activities of $\mathrm{NiO}$ octahedrons with loaded $\mathrm{AgCl}$ particles and charge separation between polar $\mathrm{NiO}\{111\}$ surfaces. Appl Catal B Environ 172: 165-173.

84. Ashrafi A, Jagadish C (2007) Review of zincblende ZnO: stability of metastable $\mathrm{ZnO}$ phases. J Appl Phys 102: 071101.

85. Jiang H, Stewart DA (2017) Using dopant to tune oxygen vacancy formation in Transition metal oxide restive memory. ACS Appl Mater Interfaces 9: 16296-16304.

86. Kabongo GL, Mhlongo GH, Mothudi BM, Hillie KT, Swart HC, et al. (2014) Enhanced exciton emission from $\mathrm{ZnO}$ nano-phosphor induced by Yb3+ ions. Materials Letters 119: 71-74.

87. Kabongo GL, Mhlongo GH, Malwela T, Mothudi BM, Hillie KT, et al. (2014) Microstructural and photoluminescence properties of sol-gel derived $\mathrm{Tb} 3+$ doped $\mathrm{ZnO}$ nanocrystals. J Alloys Compds 591: 156-163.

88. Mhlongo GH, Motaung DE, Swart HC (2015) Pd2+ doped ZnO nanostructures: Structural, luminescence and gas sensing properties. Mater Lett 160: 200-205.

89. Mhlongo GH, Shingange K, Tshabalala ZP, Dhonge BP, Mahmoud FA, et al. (2016) Room temperature ferromagnetism and gas sensing in ZnOnanostructures: Influence of intrinsic defects and $\mathrm{Mn}, \mathrm{Co}, \mathrm{Cu}$ doping. Appl Surf Sci 390: 804-815.

90. Park JH, Lee YJ, Bae JS, Kim BS, Cho YC, et al. (2015) Analysis of oxygen vacancy in co-doped $\mathrm{ZnO}$ using the electron density distribution obtained using MEM. Nanoscale Res Lett 10: 186.

91. Sreeprasad TS, Nguyen P, Kim N, Berry V (2013) Controlled, DefectGuided, Metal- Nanoparticle Incorporation onto MoS2 via Chemical and Microwave Routes: Electrical. Thermal, and Structural Properties, Nano Lett 13: 4434-4441.

92. Yoshida K, Sonobe T, Zen H, Hachiya K, Okumura K, et al. (2015) Effect of microwave irradiation on the electronic structure of $\mathrm{ZnO}$. J Phys Chem Solids 83: 47-51.

93. Khamlich S, Khamliche T, Dhlamini MS, Khenfouch M, Mothudi BM, et al. (2017) Rapid microwave-assisted growth of silver nanoparticles on 3D graphene networks for supercapacitor application. J Colloid Interface Sci 493: 130-137.

94. Ming B, Li J, Kang F, Pang G, Zhang Y, et al. (2012) Microwavehydrothermal synthesis of birnessite-type $\mathrm{MnO} 2$ nanospheres as supercapacitor electrode materials. J Power Sources 198: 428-431. 
95. Alsharaeh E, Ahmed F, Aldawsari Y, Khasawneh M, Abuhimd H, et al. (2016) Novel synthesis of holey reduced graphene oxide (HRGO) by microwave irradiation method for anode in lithium-ion batteries. Sci Rep 6: 29854.

96. Kiani A, Dastafkan K, Obeydavi A, Rahimi M (2017) Solid solutions of gadolinium doped zinc oxide nanorods by combined microwaveultrasonic irradiation assisted crystallization. Solid State Sci 74: 152-167.

97. Motaung DE, Mhlongo GH, Nkosi SS, Malgas GF, Mwakikunga BW, et al. (2014) Shape-Selective Dependence of Room Temperature Ferromagnetism Induced by Hierarchical ZnO Nanostructures. ACS Appl Mater Interfaces 6: 8981-8995.

98. Pahalagedara LR, Dharmarathna S, Kingondu CK, Pahalagedara MN, Meng YT, et al. (2014) Microwave-assisted hydrothermal synthesis of aMnO2: lattice expansion via rapid temperature ramping and framework substitution. J Phys Chem C 118: 20363-20373.

99. Mohamed RM, Aazam ES (2012) Synthesis and characterization of $\mathrm{CeO} 2-\mathrm{SiO} 2$ nanoparticles by microwave-assisted irradiation method for photocatalytic oxidation of methylene blue dye. Int J Photoenergy ID 928760.

100. Liu FW, Hsu CH, Chen FS, Lu CH (2012) Microwave-assisted solvothermal preparation and photoluminescence properties of Y2O3:Eu3+ phosphors. Ceramics International 38: 1577-1584.

101. Pahalagedara LR, Dharmarathna S, Kingondu CK, Pahalagedara MN, Meng YT, et al. (2014) Microwave-assisted hydrothermal synthesis of a$\mathrm{MnO} 2$ : lattice expansion via rapid temperature ramping and framework substitution. J Phys Chem C 118: 20363-20373.

102. Mohamed RM, Aazam ES (2012) Synthesis and characterization of $\mathrm{CeO} 2-\mathrm{SiO} 2$ nanoparticles by microwave-assisted irradiation method for photocatalytic oxidation of methylene blue dye. Int J Photoenergy ID 928760.

103. Hai-Bo F, Shao-Yan Y, Pan-Feng Z, Hong-Yuan W, Xiang-Lin L, et al. (2007) Investigation of oxygen vacancy and interstitial oxygen defects in zno films by photoluminescence and $\mathrm{x}$-ray photoelectron spectroscopy. Chinese Phys Lett 24: 2108.

104. Liu LZ, Li TH, Wu XL, Shen JC, Chu PK (2012) Identification of oxygen vacancy types from Raman spectra of $\mathrm{SnO} 2$ nanocrystals. J Raman Spectrosc 43: 1423-1426.

105. Nishida K, Osada M, Takeuchi H, Yosiaki I, Sakai J, et al. (2008) Raman spectroscopy study of oxygen vacancies in $\mathrm{PbTiO} 3$ thin films generated heat-treated in hydrogen atmosphere. J Appl Phys 47: 7510-7513.

106. Guo M, Lu J, Wu Y, Wang Y, Luo M (2011) UV and visible raman studies of oxygen vacancies in rare-earth-doped ceria. Langmuir 27: 3872-3877.

107. Wang ZL, Yin JS, Jiang YD (2000) EELS analysis of cation valence states and oxygen vacancies in magnetic oxides. Micron 31: 571-580.

108. Wu QH, Thissen A, Jaegermann W, Liu M (2004) Photoelectron spectroscopy study of oxygen vacancy on vanadium oxides surface. Appl Surf Sci 236: 473-478

109. Kumar V, Swart HC, Ntwaeaborwa OM, Kroon RE, Terblans JJ, et al. (2013) Origin of the red emission in zinc oxide nanophosphors. Materials Letters 101: 57-60.

110. Li Y, Feng Y, Zhou Q, Wu M, Mi J (2017) Effects of microwave irradiation on the structure of Zinc oxide sorbents for high temperature coal gas desulfurization. Energy Fuels 31: 8512-8520.

111. Yang H, Wang YQ, Jia QX (2010) Oxygen concentration and its effect on the leakage current in BiFeO3, thin films. Appl Phys Lett 96: 012909.

112. Ciatto G, Di Trolio A, Fonda E, Alippi P, Testa AM (2011) Evidence of Cobalt-Vacancy Complexes in Zn1-x CoxO. Phys Rev Lett 107: 127206.

113. Yan D, Wang W, Luo X, Chen C, Zeng Y, et al. (2018) NiCo2O4 with oxygen vacancies as better performance electrode material for supercapacitor. Chem Eng J 334: 864-872.

114. Zhai T, Xie S, Yu M, Fang P, Liang C, et al. (2014) Oxygen vacancies enhancing capacitive properties of $\mathrm{MnO} 2$ nanorods for wearable asymmetric supercapacitors. Nano Energy 8: 255-263.

115. Dillip GR, Banerjee AN, Anitha VC, Raju BDP, Joo SW, et al. (2016) Oxygen vacancy-induced structural, optical, and enhanced supercapacitive performance of zinc oxide anchored graphitic carbon nanofiber hybrid electrodes. ACS Appl Mater Interfaces 8: 5025-5039.

116. Xiang K, Xu Z, Qu T, Tian Z, Zhang Y, et al. (2017) Two dimensional oxygen-vacancy-rich $\mathrm{Co} 3 \mathrm{O} 4$ nanosheets with excellent supercapacitor performances. Chem Commun 53: 12410.

117. Guo W, Sun W, Wang Y (2015) Multilayer CuO@NiO hollow spheres: microwave- assisted metal-organic-framework derivation and highly reversible structure-matched stepwise lithium storage. ACS Nano 9: 11462-11471.

118. Li GC, Liu PF, Liu R, Liu M, Tao K, et al. (2016) MOF-derived hierarchical double-shelled $\mathrm{NiO} / \mathrm{ZnO}$ hollow spheres for highperformance supercapacitors. Dalton Trans 45: 13311.

119. Zhai T, Xie S, Yu M, Fang P, Liang C, et al. (2014) Oxygen vacancies enhancing capacitive properties of $\mathrm{MnO} 2$ nanorods for wearable asymmetric supercapacitors Nano Energy 8: 255-263.

120. Salunkhe RR, Kaneti YV, Yamauchi Y (2017) Metal-organic frameworkderived nanoporous metal oxides toward supercapacitor applications: progress and prospects. ACS Nano 11: 5293-5308.

121. Ge X, Li Z, Wang C, Yin L (2015) Metal-organic frameworks derived porous core/shell structured $\mathrm{ZnO} / \mathrm{ZnCo} 2 \mathrm{O} 4 / \mathrm{C}$ hybrids as anodes for high-performance lithium-ion battery. ACS Appl Mater Interfaces 7: 26633-26642.

122. Dembele A, Rahman M, MacElroy JMD, Dowling DP (2012) Evaluation of microwave plasma sintering for the fabrication of dye sensitized solar cell (DSSC) electrodes. J Nanosci Nanotechnol 12: 4769-74.

123. Cao Q, Yang S, Gao Q, Lei L, Yu Y, et al. (2016) Fast and controllable crystallization of perovskite films by microwave irradiation process. ACS Appl Mater Interfaces 8: 7854-7861.

124. Po-Shen S, Chuan-Ming T, Ta-Chuan K, Ching-Kuei S, Ming-Hsien L, et al. (2015) Microwave-assisted synthesis of titanium dioxide nanocrystalline for efficient dye-sensitized and perovskite solar cells. Solar Energy 120: 345-356.

125. Liu H, Wu Z, Gao H, Shao J, Zou H, et al. (2017) One-step preparation of cesium lead halide $\mathrm{CsPbX} 3(\mathrm{X}=\mathrm{Cl}, \mathrm{Br}$, and $\mathrm{I}$ ) perovskite nanocrystals by microwave irradiation. ACS Appl Mater Interfaces 9: 42919-42927.

126. Abulikemu M, Neophytou M, Barbe JM, Tietze ML, El Labban A, et al. (2017) Microwave-synthesized tin oxide nanocrystals for lowtemperature solution-processed planar junction organo-halide perovskite solar cells. J Mater Chem A 5: 7759-7763.

127. Menzies DB, Dai Q, Cheng YB, Simon GP, Spiccia L (2006) One-step microwave calcination of $\mathrm{ZrO} 2$-coated $\mathrm{TiO} 2$ electrodes for use in dyesensitized solar cells. C R Chimie 9: 713-716.

128. Uchida S, Tomiha M, Masaki N, Miyazawa A, Takizawa H (2004) Preparation of $\mathrm{TiO} 2$ nanocrystalline electrode for dye-sensitized solar cells by $28 \mathrm{GHz}$ microwave irradiation. Sol Energy Mater Sol Cells 81 : 135-139.

129. Wang HE, Zheng LX, Liu CP, Liu YK, Luan CY, et al. (2011) Rapid microwave synthesis of porous $\mathrm{TiO} 2$ spheres and their applications in dye-sensitized solar cells. J Phys Chem C 115: 10419-10425.

130. Hart JN, Cervinia R, Chenga YB, Simona GP, Spiccia L (2004) Formation of anatase $\mathrm{TiO} 2$ by microwave processing. Sol Energy Mater Sol Cells 84: 135-143

131. Su T, Yang Y, Na Y, Fan R, Li L, et al. (2015) An Insight into the Role of Oxygen Vacancy in Hydrogenated TiO2 Nanocrystals in the Performance of Dye-Sensitized Solar Cells. ACS Appl Mater Interfaces 7: 3754-3763.

132. Hart JN, Menzies D, Cheng YB, Simon GP, Spiccia L (2006) Microwave processing of $\mathrm{TiO} 2$ blocking layers for dye-sensitized solar cells. J Sol-Gel Sci Techn 40: 45-54.

133. Ghosh D, Halder G, Sahasrabudhe A, Bhattacharyya S (2016) A microwave synthesized CuxS and graphene oxide nanoribbon composite as a highly efficient counter electrode for quantum dot sensitized solar cells. Nanoscale 8: 10632.

134. Wang M, Wang Y, Liu J, Pei C, Liu B, et al. Enhanced sensing performance and sensing mechanism of hydrogenated $\mathrm{NiO}$ particles. Sensors Actuators B 250: 208-214. 
Citation: Kabongo GL, Nyongombe G, Ozoemena K, Dhlamini S (2018) Microwave Irradiation Induces Oxygen Vacancy in Metal Oxides based Materials and Devices: A Review. J Nanosci Curr Res 3: 125. doi:10.4172/2572-0813.1000125

Page 13 of 13

135. Felix S, Chakkravarthy RBP, Grace AN (2015) Microwave assisted synthesis of copper oxide and its application in electrochemical sensing. IOP Conf Ser Mater Sci Eng 73: 012115.

136. Alali KT, Lu Z, Zhang H, Liu J, Liu Q, et al. (2017) P-p heterojunction $\mathrm{CuO} / \mathrm{CuCo} 2 \mathrm{O} 4$ nanotubes synthesized via electrospinning technology for detecting n-propanol gas at room temperature. Inorg Chem Front 4: 1219-1230.

137. Motaung DE, Mhlongo GH, Makgwane PR, Dhonge BP, Cummings FR, et al. (2018) Ultra-high sensitive and selective $\mathrm{H} 2$ gas sensor manifested by interface of $n-n$ heterostructure of $\mathrm{CeO} 2-\mathrm{SnO} 2$ nanoparticles. Sensors Actuators B: Chemi 254 : 984-995

138. Azam A, Habib SS, Salah NA, Ahmed F (2013) Microwave-assisted synthesis of $\mathrm{SnO} 2$ nanorods for oxygen gas sensing at room temperature. Int J Nanomedicine 8: 3875-3882.

139. Shingange $\mathrm{K}$, Tshabalala ZP, Ntwaeaborwa OM, Motaung DE, Mhlongo GH (2016) Highly selective NH3 gas sensor based on Au loaded ZnO nanostructures prepared using microwave-assisted method. J Colloid Interf Sci 479: 127-138.

140. Luo LB, Wang XH, Xie C, Li ZJ, Lu R, et al. (2014) One-dimensional CuO nanowire: synthesis, electrical, and optoelectronic devices application. Nanoscale Res Lett 9: 637.

141. Su XF, Chen JB, He RM, Li Y, Wang J et al. (2017) The preparation of oxygen-deficient $\mathrm{ZnO}$ nanorod arrays and their enhanced field emission. Mater Sci Semicond Process 67: 55-61.

142. Su J, Ye S, Yi X, Lu FQ, Yang XB, et al. (2017) Influence of oxygen vacancy on persistent luminescence in $\mathrm{ZnGa} 2 \mathrm{O} 4: \mathrm{Cr} 3+$ and identification of electron carriers. 7: 734-743.
143. Zhang J, Wang X, Zhang X, Zhao X, Liu X, et al. (2011) Microwave synthesis of $\mathrm{NaLa}(\mathrm{MoO} 4) 2$ microcrystals and their near-infrared luminescent properties with lanthanide ion doping $(\mathrm{Er} 3+, \mathrm{Nd} 3+, \mathrm{Yb} 3+)$. Inorg Chem Communi 14: 1723-1727.

144. Zhang Y, Xu J, Cui Q, Yang B (2017) Eu3+-doped Bi4Si3O12 red phosphor for solid state lighting: microwave synthesis, characterization, photoluminescence properties and thermal quenching mechanisms. Sci Rep 7: 42464.

145. Liu FW, Hsu CH, Chen FS, Lu CH (2012) Microwave-assisted solvothermal preparation and photoluminescence properties of Y2O3:Eu3+ phosphors. Ceramics Int 38: 1577-1584.

146. Aijaz S, Ahmed AS, Pandey RS, Choubey RK (2017) Synthesis, structural and optical properties of transition metal doped $\mathrm{ZnO}$ Nanoparticles. In: Jain V, Rattan S, Verma A (eds) Recent Trends in Materials and Devices. Springer Proceedings in Physics 178: 205-210.

147. Zhang S, Hu Y, Duan H (2016) Phosphorescence performance of La3GaGe5O16:Tb3+ by enhancing the bridging oxygen vacancies. Opt Mat Exp 6: 1998-2013.

148. Freysoldt C, Grabowski B, Hickel T, Neugebauer J, Kresse G (2014) "First principles calculations for point defects in solids". Rev Mod Phys 86: 253-304.

149. Xu X, Wang Y, Gong Y, Zeng W, Li Y (2010) Effect of oxygen vacancies on the red phosphorescence of $\mathrm{Sr} 2 \mathrm{SnO} 4: \mathrm{Sm} 3+$ phosphor. Opt Exp 18: 16989-16994.

150. Liao AZ, Chen JB, Wang CW, Su XF, Li Y, et al. (2016) Enhanced field emission properties from oxygen-deficient a-Fe2O3 nanorod arrays. J Vac Sci Technol B 34: 021803. 